\title{
One new genus and nineteen new species of ground spiders (Araneae: Gnaphosidae) from Iran, with other taxonomic considerations
}

\author{
Alireza ZAMANI ${ }^{1, *}$, Maria CHATZAKI ${ }^{2}$, \\ Sergei L. ESYUNIN ${ }^{3} \&$ Yuri M. MARUSIK ${ }^{4}$ \\ ${ }^{1}$ Zoological Museum, Biodiversity Unit, University of Turku, FI-20014, Finland. \\ ${ }^{2}$ Department of Molecular Biology and Genetics, Democritus University of Thrace, \\ Dragana, 68100 Alexandroupolis, Greece. \\ ${ }^{3}$ Perm State University, Bukireva Street 15, Perm, 614600, Russia. \\ ${ }^{4}$ Institute for Biological Problems of the North RAS, \\ Portovaya Str.18, Magadan, 685000, Russia. \\ ${ }^{4}$ Department of Zoology \& Entomology, University of the Free State, \\ Bloemfontein 9300, South Africa. \\ *Corresponding author: zamani.alireza5@gmail.com \\ 2Email: maria.chatzaki@gmail.com \\ ${ }^{3}$ Email: Sergei.Esyunin@psu.ru \\ ${ }^{4}$ Email: yurmar@mail.ru \\ ${ }^{1}$ urn:1sid:zoobank.org:author:A21C0B82-E2D9-4402-9408-D6160843DAF4 \\ ${ }^{2}$ urn:1sid:zoobank.org:author:2FBB48ED-84FE-4386-8F47-C958E9F8A2A1 \\ ${ }^{3}$ urn:lsid:zoobank.org:author:2B591857-5FAB-4B7D-B589-6C4977A3A493 \\ ${ }^{4}$ urn:lsid:zoobank.org:author:F215BA2C-5072-4CBF-BA1A-5CCBE1626B08
}

\begin{abstract}
One new genus, Zagrotes gen. nov., and 19 new species of ground spiders (Gnaphosidae) are described from Iran: Berinda bifurcata sp. nov. ( ${ }^{\lambda}$, Bushehr, Khuzestan; southwestern and southern Iran), Berinda hoerwegi sp. nov. ( $\jmath^{\lambda}+$, Fars, Ilam, Kermanshah, Kurdistan; western and southcentral Iran), Berlandina artaxerxes sp. nov. (ð Yazd; central Iran), Cryptodrassus iranicus sp. nov. (ठิ, Kermanshah; western Iran), Drassodes persianus sp. nov. ( 9 , Kermanshah, Sistan \& Baluchistan; western and southeastern Iran), Echemus caspicus sp. nov. (, , Golestan; northern Iran), Gnaphosa qamsarica sp. nov. (†, Isfahan; central Iran), Haplodrassus medes sp. nov. ( $\hat{O}$, Fars; southcentral Iran), Haplodrassus qashqai sp. nov. ( $\hat{O} \bigcirc$, Hormozgan, Khuzestan, Lorestan; southwestern to southern Iran), Marinarozelotes achaemenes sp. nov. ( $\circ$, Kohgiluyeh \& Boyer-Ahmad; southwestern Iran), Marjanus isfahanicus sp. nov. ( $\$$, Isfahan; central Iran), Nomisia ameretatae sp. nov. ( $\$$, Tehran; northern Iran), Prodidomus inexpectatus sp. nov. (ঐ), Hormozgan; southern Iran), Scotophaeus anahita sp. nov. ( $\odot$, Isfahan; central Iran), Scotophaeus elburzensis sp. nov. (q, Tehran, Zanjan; northwestern and northern Iran), Sosticus

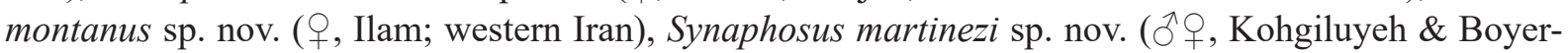
Ahmad; southwestern Iran), Zagrotes apophysalis sp. nov. ( $ð$ † , Hormozgan, Kohgiluyeh \& BoyerAhmad; southwestern to southern Iran) and Zelotes hyrcanus sp. nov. ( + , Mazandaran; northern Iran). These are the first records of the genera Berinda Roewer, 1928, Echemus Simon, 1878 and Marjanus Chatzaki, 2018 in Iran. Additionally, the previously unknown female of Callipelis deserticola Zamani \&
\end{abstract}


Marusik, 2017 is described and illustrated, and Berlandina mesopotamica Al-Khazali, 2020 is recorded in Iran for the first time. Furthermore, Berinda idae Lissner, 2016 syn. nov. (Greece, Cyprus) is synonymized with Berinda infumatus (O. Pickard-Cambridge, 1872) comb. nov. (ex. Heser Tuneva, 2004; Greece, Tanzania, Egypt, Israel, introduced to Japan).

Keywords. Middle East, new combination, new record, new synonymy.

Zamani A., Chatzaki M., Esyunin S.L. \& Marusik Y.M. 2021. One new genus and nineteen new species of ground spiders (Araneae: Gnaphosidae) from Iran, with other taxonomic considerations. European Journal of Taxonomy 751: $68-114$. https://doi.org/10.5852/ejt.2021.751.1381

\section{Introduction}

Gnaphosidae Pocock, 189, commonly known as ground spiders, is the fourth largest family of spiders with 2549 currently recognized extant species in 162 genera worldwide (WSC 2021). Currently, 111 species in 35 genera of gnaphosids are known from Iran (Zamani et al. 2021). Most of the regional data on this family is known as a result of the large-scale faunistic series by Zamani et al. (2014, 2015, 2016, 2017 , 2018a, 2019, 2020), as well as other scattered records gathered from local, mostly provincial-level surveys (e.g., Mozaffarian et al. 2000; Komposch 2002; Kashefi et al. 2013; Zamani 2015; Namaghi et al. 2016; Sadeghi et al. 2016; Zamani \& Mozaffarian 2017; Zamani \& Marusik 2018; Hosseinpour et al. 2019). The number of taxonomic papers is scarcer (e.g., Roewer 1955; Senglet 2012; Marusik et al. 2013; Zamani \& Marusik 2017; Zamani et al. 2018b; Esyunin \& Zamani 2019), and overall, this family is poorly studied in the region, with only five Iranian endemic species currently listed by Zamani et al. (2021). Therefore, the present study was carried out on Iranian gnaphosid material collected by two of the authors as well as on specimens deposited in institutional collections in Europe, yielding the discovery of one new genus and 19 new species, the first record of the female of the monotypic genus Callipelis Zamani \& Marusik, 2017 as well as the first record of Berlandina mesopotamica Al-Khazali, 2020 in Iran. All these discoveries are described and illustrated in this paper. Additionally, new taxonomic considerations within the genus Berinda Roewer, 1928, including a new combination and a new synonymy, are proposed.

\section{Material and methods}

Specimens were photographed using an Olympus Camedia E-520 camera attached to an Olympus SZX16 stereo microscope and a JEOL JSM-5200 scanning electron microscope at the Zoological Museum of University of Turku, or an Olympus OMD EM-10 digital camera with a Panasonic Lumix H-H025 25 mm f/1.7 lens mounted on a Zeiss microscope at Perm State University. Digital images were prepared using CombineZP image stacking software. Illustrations of internal genitalia were made after clearing them in a $10 \% \mathrm{KOH}$ aqueous solution. Lengths of leg segments were measured on the dorsal side and listed as: total length (femur, patella, tibia, metatarsus, tarsus). All measurements are given in millimeters.
Abbreviations
Eyes
$\mathrm{ALE}=$ anterior lateral eye
$\mathrm{AME}=$ anterior median eye
PLE $=$ posterior lateral eye
$\mathrm{PME}=$ posterior median eye 


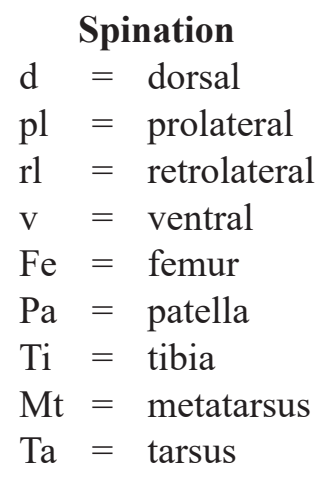

Repositories (curators' names in parentheses)

MHNG = Muséum d'histoire naturelle, Genève, Switzerland (P.J. Schwendinger)

MMUE = Manchester Museum of the University of Manchester, United Kingdom (D.V. Logunov)

NHMW $=$ Naturhistorisches Museum Wien, Vienna, Austria (C. Hörweg)

PSU $\quad=$ Zoological Museum of Perm State University, Perm, Russia (S.L. Esyunin)

SMF = Senckenberg Museum, Frankfurt am Main, Germany (P. Jäger, J. Altmann)

ZMMU = Zoological Museum of Moscow University, Moscow, Russia (K.G. Mikhailov)

\title{
Results
}

\author{
Class Arachnida Lamarck, 1801 \\ Order Araneae Clerck, 1757 \\ Family Gnaphosidae Pocock, 1898
}

Genus Berinda Roewer, 1928

Berinda Roewer, 1928: 106.

Berinda - Murphy 2007: 37. - Panayiotou et al. 2010: 45.

\section{Type species}

Berinda amabilis Roewer, 1928.

\section{Comments}

This is a small genus with seven named species that are restricted to the Eastern Mediterranean from Greece to Anatolia. The new species collected in Iran represent the southeasternmost records of the genus. Compared to other gnaphosids, homology of the male palpal structures in this genus is unclear, as it is questionable whether the sclerotized hook-like structure ("posterior hook" sensu Panayiotou et al. 2010) that guides the tip of the embolus is a greatly modified median apophysis or not. Here, we treat the hook-like structure as a median apophysis.

While comparing our specimens to the species reported from Europe, we realized that Berinda idae Lissner, 2016 (described from Greece and later reported from Cyprus) is undoubtedly a junior synonym of Heser infumatus (O. Pickard-Cambridge, 1872) (from Greece, Tanzania, Egypt and Israel; introduced to Japan). The copulatory organs are identical (cf. Lissner \& Chatzaki 2016: figs 2-3 and Levy 1998: figs 112-115) and both have been recorded from Greek islands. The long filiform embolus, robust conductor and distinctive tibial apophysis conform to Berinda rather than Heser Tuneva, 2004 (see Panayiotou et al. 2010). Thus, a generic transfer is proposed, resulting in the new combination Berinda infumatus comb. nov. (O. Pickard-Cambridge, 1872). 


\section{Berinda bifurcata sp. nov.}

urn:lsid:zoobank.org:act:C7BAB75D-0F99-4B2A-9483-BB7BADF415B0

Fig. 1

\section{Diagnosis}

This new species differs from all congeners by the deeply bifurcated retrolateral tibial apophysis (vs two apophyses in B. cypria Chatzaki \& Panayiotou, 2010, or one apophysis shallowly [in the upper $1 / 3$ ] bifurcated or not bifurcated in other species).
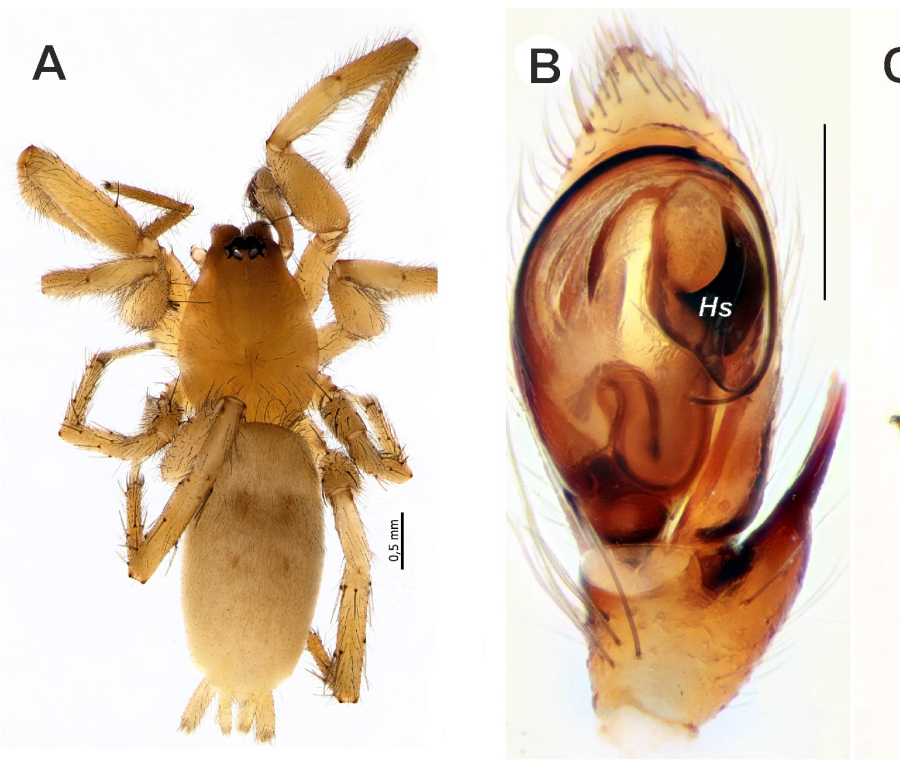

C
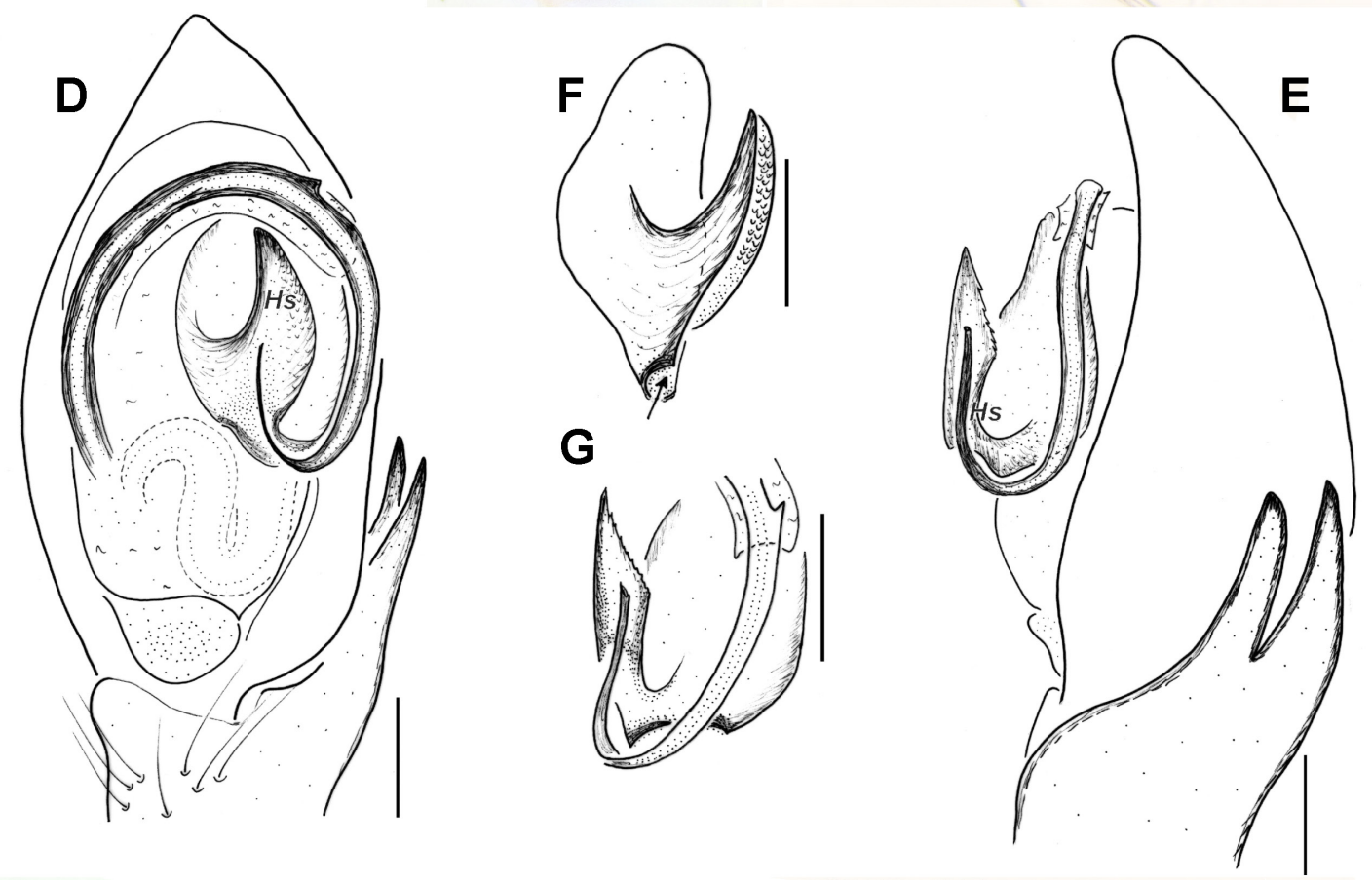

Fig. 1. Berinda bifurcata sp. nov., holotype, ô (MHNG). A. Habitus, dorsal view. B, D. Palp, ventral view. C, E. Palp, retrolateral view. F-G. Hook-like structure, proventral and retrolateral views; arrow points to the entrance for the embolus. Abbreviation: $H s=$ hook-like structure. Scale bars: $\mathrm{A}=0.5 \mathrm{~mm}$; $\mathrm{B}=0.2 \mathrm{~mm} ; \mathrm{D}-\mathrm{G}=0.1 \mathrm{~mm}$. 


\title{
Etymology
}

The specific epithet is an adjective and refers to the unique bifurcated retrolateral tibial apophysis of the male palp.

\section{Type material}

\section{Holotype}

IRAN・ ○’; Khuzestan Province, Dezful; Mar. 2018; A. Zamani leg.; MHNG.

\section{Paratype}

IRAN・ 1 ○े; Bushehr Province, Khormoj; 7 Feb. 1984; K. Elmi leg.; MMUE.

\section{Description}

Male (holotype)

Habitus as in Fig. 1A. Total length 4.02. Carapace 1.60 long, 1.21 wide. Eye sizes and interdistance of PMEs: $\mathrm{AME}=0.11, \mathrm{ALE}=0.09, \mathrm{PME}=0.10, \mathrm{PLE}=0.08, \mathrm{PME}-\mathrm{PME}=0.05$. Carapace, sternum, labium, chelicerae and maxillae yellowish, without any pattern and with slightly darker margins. Chelicera with 4 pro- and 3 retromarginal teeth. Legs the same color as carapace, without annulations. Abdomen light yellowish, without any pattern, dorsally with two pairs of sigilla, anteriorly with a series of long setae and a small, triangular scutum. Spinnerets uniform in color and slightly lighter than abdomen. Measurements of legs: I: 5.07 (1.34, 0.87, 1.12, 0.97, 0.77), II: 3.53 (1.12, 0.46, 0.78, 0.56, 0.61), III: 3.43 (0.88, 0.54, $0.62,0.77,0.62)$, IV: $5.32(1.40,0.73,1.17,1.30,0.72)$.

Palp as in Fig. 1B-G. Femur and patella unmodified; femur as long as cymbium; tibial apophysis deeply bifurcated, both arms subequal in size and length, as long as tibia's length; guiding hook-like structure $(H s)$ (sensu Panayiotou at al. 2010) located in anterior half of the bulb and directed anteriorly; spermophor coiled, located in posterior half of the bulb; embolus long, filiform, originating at about $9 \mathrm{o}$ 'clock position, proximal part with membranous mesal part, with a small tooth at the retrolateral anterior part of the loop, terminal part bent perpendicular to the plane of the cymbium.

\section{Female}

Unknown.

\section{Distribution}

Known only from the listed localities in Bushehr and Khuzestan Provinces, southwestern Iran. This is the first record of Berinda in Iran, and the southeasternmost record of the genus.

\author{
Berinda hoerwegi sp. nov. \\ urn:1sid:zoobank.org:act:C322064D-4C9C-4FE5-A6AE-1403E560CA55
}

Fig. 2

\section{Diagnosis}

Males of this species differ from all congeners by the tibial apophysis being rectangular with a blunt end (vs with tapering tip) and by the distinct form of the median apophysis (= conductor sensu Panayiotou et al. 2010), with the sclerotized part directed terminally (vs laterally in B. aegilia Chatzaki, 2002 and B. amabilis Roewer, 1928 or hook-like in B. ensigera (O. Pickard-Cambridge, 1874), B. cooki Logunov, 2012, B. cypria Chatzaki \& Panayiotou, 2010 and B. hakani Chatzaki \& Seyyar, 2010). Females of $B$. hoerwegi sp. nov. are mostly similar to those of $B$. aegilia but can be distinguished by the smaller conical anterior hood $(A h)$ (vs rectangular) and longer copulatory ducts. 


\section{Etymology}

This species is named after Mr Christoph Hörweg, the curator of Arachnology at NHMW, for helping the first author during his visit to Vienna.
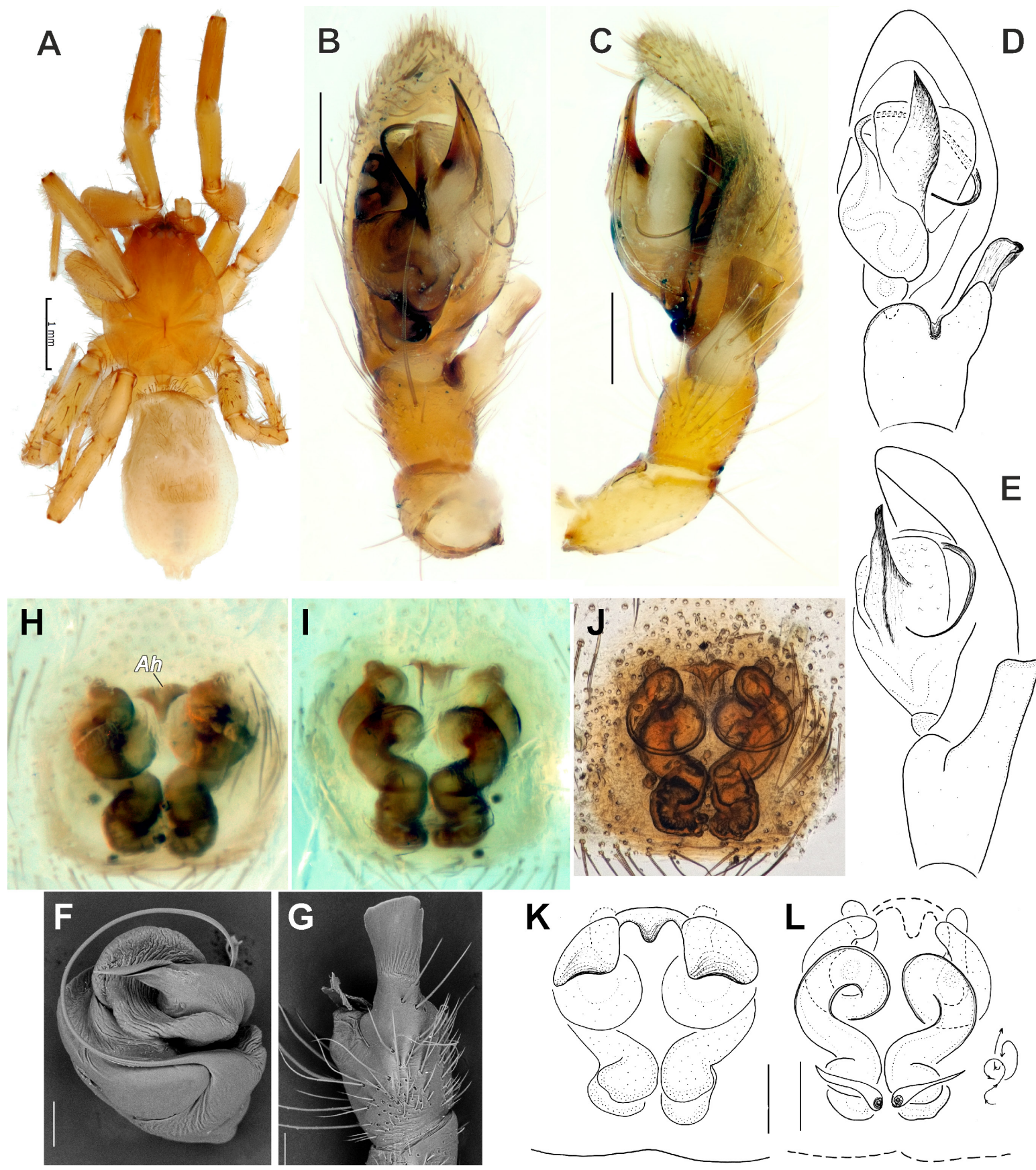

Fig. 2. Berinda hoerwegi sp. nov. (A-E = holotype, $\widehat{\partial}$, MHNG; F-G = paratype, $\widehat{\partial}$ from Kermanshah Provinve, MHNG ; H-L = paratype, $q$ from Ilam Province, MHNG). A. Habitus, dorsal view. B-E. Palp, ventral, retrolateral and retroventral views. F. Apical portion of bulb. G. Tibial apophysis, retrolateral view. H, J-K. Epigyne, ventral view. I. Epigyne, dorsal view. L. Same, with schematic course of internal duct system. Abbreviation: $A h=$ anterior hood. Scale bars: A $=1 \mathrm{~mm} ; \mathrm{B}-\mathrm{C}=0.2 \mathrm{~mm} ; \mathrm{F}-\mathrm{G}, \mathrm{K}-\mathrm{L}=0.1 \mathrm{~mm}$. 


\section{Type material}

Holotype

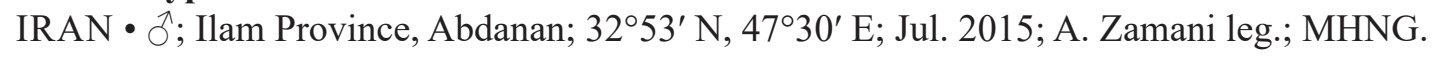

\section{Paratypes}

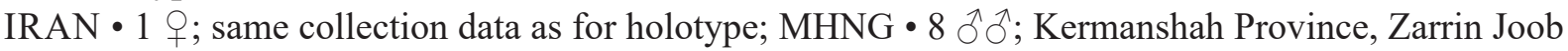
Vil.; Apr. 2017; M. Amiri leg.; MHNG • 1 क; Kurdistan Province, Marivan; May 2017; A. Zamani leg.; MHNG • 1 ठ̊; Fars Province, 5 km N of Persepolis; 1970; K. Bilek leg.; NHMW.

\section{Description}

\section{Male (holotype)}

Habitus as in Fig. 2A. Total length 4.50. Carapace 1.92 long, 1.50 wide. Eye sizes and interdistance of PMEs: $\mathrm{AME}=0.09, \mathrm{ALE}=0.12, \mathrm{PME}=0.12, \mathrm{PLE}=0.12, \mathrm{PME}-\mathrm{PME}=0.03$. Carapace, chelicerae, sternum, maxillae and labium light reddish brown. Chelicera with 2 pro- and 5 retromarginal teeth. Legs slightly lighter than carapace, without annulations, and with numerous spines (III and IV). Abdomen light brown, without any markings and with a small scutum anteriorly. Spinnerets light gray. Measurements of legs: I: 7.29 (1.77, 1.33, 1.66, 1.50, 1.03), II: 5.35 (1.41, 0.87, 1.13, 1.08, 0.86), III: 4.41 (1.19, 0.68, $0.82,1.01,0.71)$, IV: $7.07(1.81,1.06,1.67,1.71,0.82)$.

Palp as in Fig. 2B-G. Femur unmodified; patella slightly longer than tibia (not including apophysis); tibial apophysis as long as tibia, with swollen base and flat anterior part, margins parallel; cymbium 2 times as long as wide, its width as long as tibia; spermophor coiled; median apophysis (= conductor sensu Panayiotou at al. 2010) large, sharply pointed; filamentous embolus originates almost from the center of the bulb, makes $360^{\circ}$ loop.

Female (paratype from Ilam Province)

Carapace 3.05 long, 2.28 wide (abdomen missing). Eye sizes and interdistance of PMEs: $\mathrm{AME}=0.13$, $\mathrm{ALE}=0.15, \mathrm{PME}=0.13, \mathrm{PLE}=0.12, \mathrm{PME}-\mathrm{PME}=0.05$. Coloration and habitus features as in male. Measurements of legs: I: 8.79 (2.30, 1.73, 1.86, 1.69, 1.21), II: 6.99 (1.92, 1.26, 1.55, 1.34, 0.92), III: $4.41(1.19,0.68,0.82,1.01,0.71)$, IV: $6.04(1.65,1.00,1.12,1.39,0.88)$.

Epigyne as in Fig. 2H-L. Epigyne with small, conical anterior hood, and lateral plates with copulatory openings located posteriorly in relation to the hood; copulatory ducts long, extending to the edges of the epigynal plate with two full coils, continuing posteriorly to two small, oval spermathecae.

\section{Distribution}

Known from the listed localities in Ilam, Kermanshah, Kurdistan and Fars Provinces, western and southcentral Iran.

Genus Berlandina Dalmas, 1922

Berlandina artaxerxes sp. nov. urn:1sid:zoobank.org:act:AA010096-605E-4BFD-A7D7-8797A2B89B34

Fig. 3A-D

\section{Diagnosis}

The new species is most similar to B. venatrix (O. Pickard-Cambridge, 1874) and B. koponeni Marusik, Fomichev \& Omelko, 2014 by having a broad embolar base $(E b)$ with a similar sclerotized apical outgrowth $(\mathrm{Ao})$ parallel to a bent, long embolus and a basal process $(\mathrm{Po})$. In the new species, the two 
elements of the embolar base are pointed (vs shallowly divided with the process small and curved in B. koponeni; see Marusik et al. 2014: figs 32,34, and the basal process bearing a very pointed sclerotized tooth in B. venatrix; see Levy 1995: fig. 57, not present in B. artaxerxes sp. nov.). Also, the median apophysis in $B$. artaxerxes sp. nov. is bent prolaterally and located under the apical outgrowth's curve (vs straight and longer, reaching the height of the embolus in B. koponeni; see Marusik et al. 2014: figs 34-35).
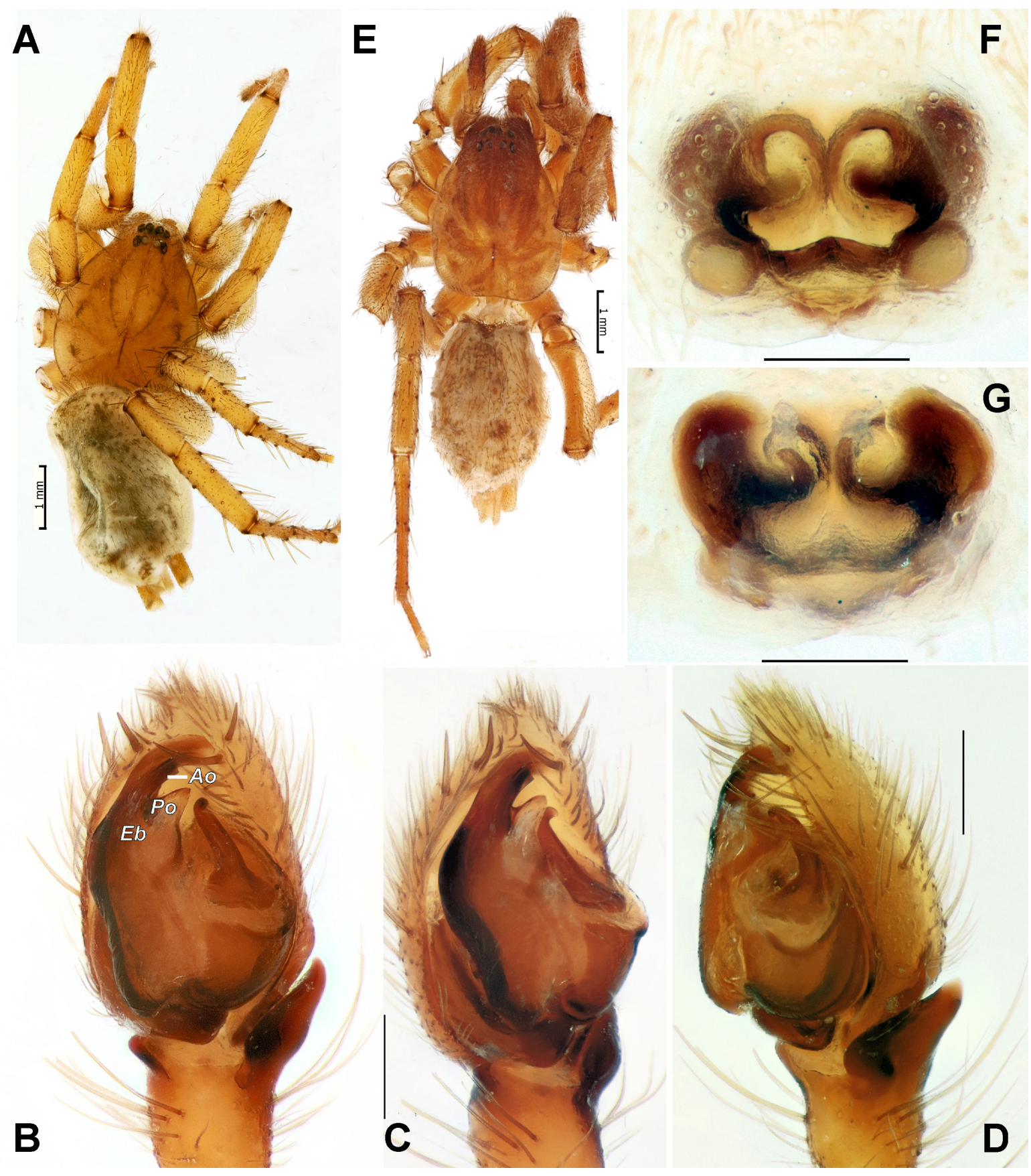

Fig. 3. A-D. Berlandina artaxerxes sp. nov., holotype, ठ̊ (SMF). A. Habitus, dorsal view. B-D. Palp, ventral, proventral and retrolateral views. - E-G. Berlandina mesopotamica Al-Khazali, 2020, o (MHNG). E. Habitus, dorsal view. F-G. Epigyne, ventral and dorsal views. Abbreviations: Ao= apical outgrowth; $E b=$ embolar base; $P o=$ pointed process. Scale bars: $0.2 \mathrm{~mm}$, unless stated otherwise. 


\section{Etymology}

The specific epithet is a noun in apposition and refers to Ardashir I (equivalent to Greek Artaxérxēs), the founder of the Sasanian Empire.

\section{Type material}

\section{Holotype}

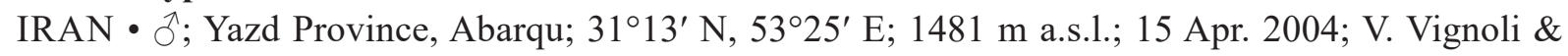
P. Crucitti leg.; SMF.

\section{Description}

\section{Male}

Habitus as in Fig. 3A. Total length 5.55. Carapace 2.95 long, 2.15 wide. Eye sizes and interdistance of PMEs: $\mathrm{AME}=0.13, \mathrm{ALE}=0.13, \mathrm{PME}=0.13, \mathrm{PLE}=0.15, \mathrm{PME}-\mathrm{PME}=0.07$. Carapace, sternum, labium, chelicerae and maxillae yellowish brown; carapace with small dark submarginal patches. Chelicera with a small tooth on promargin and a serrated, bifurcate keel on retromargin. Legs the same color as carapace, without annulations. Abdomen gray, without any clear pattern, although some brown markings are visible. Spinnerets light brown and uniform in color. Measurements of legs: I: $7.00(1.95,1.12,1.54,1.31,1.08)$, II: 6.29 (1.68, 1.08, 1.24, 1.26, 1.03), III: $5.04+$ missing Ta (1.62, 0.99, 0.94, 1.49, Ta missing), IV: 8.58 $(2.25,1.20,1.49,2.39,1.25)$.

Palp as in Fig. 3B-D. Tibia with massive apophysis, as long as tibia, pointed tip directed dorso-anteriorly with angle about $45^{\circ}$ to the axis of the palp; cymbium ovoid, 1.6 times as long as wide; median apophysis long, oblique, about as long as tibial apophysis; embolar base $(E b)$ complex, with 2 outgrowths: a basal pointed process $(P o)$ weakly sclerotized, and a sclerotized apical outgrowth $(A o)$ [tip appears broken] parallel to a bent, long embolus; embolus proper gently curved and making a course of about $90^{\circ}$.

\section{Female}

Unknown.

\section{Distribution}

Known only from the type locality in Yazd Province, central Iran.

Berlandina mesopotamica Al-Khazali, 2020

Figs $3 \mathrm{E}-\mathrm{G}, 4$

Berlandina mesopotamica - Al-Khazali \& Fomichev, 2021: 70, figs 1a-e, 2a-c (P).

\section{Material examined}

IRAN • 2 q 9 ; Bushehr Province, close to the Persian Gulf; $28^{\circ} 56^{\prime}$ N, 5049’ E; 30 May 1974; A. Senglet leg.; MHNG.

\section{Comments}

For diagnosis and descriptions see Al-Khazali (2020) and Al-Khazali \& Fomichev (2021).

\section{Distribution}

Previously known only from southeastern Iraq. New to Iran, with the current material representing the southeasternmost record of the species across its known range. 


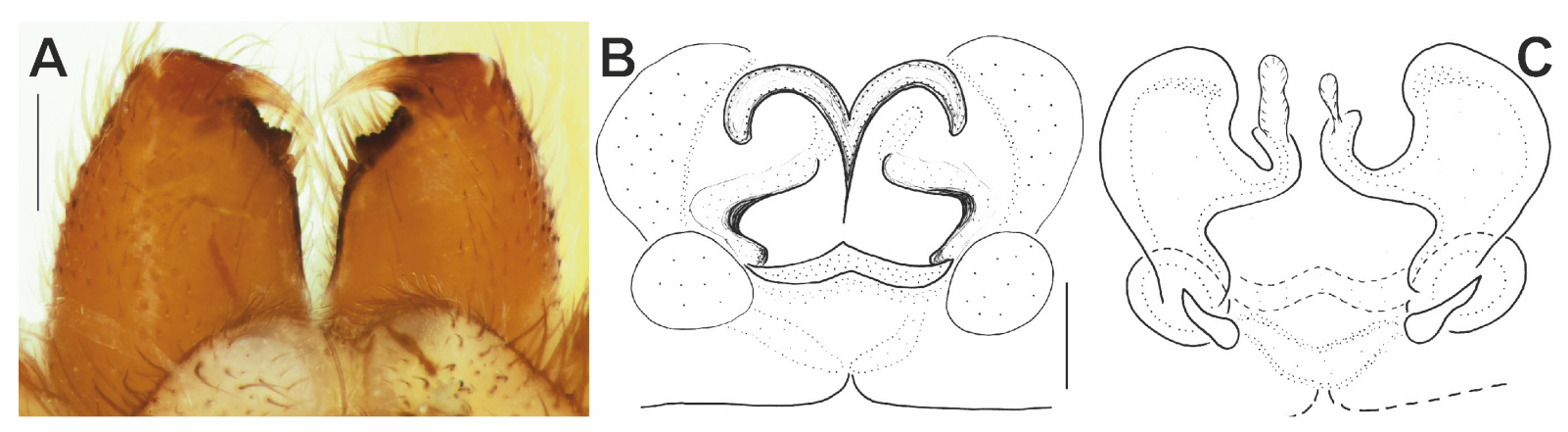

Fig. 4. Berlandina mesopotamica Al-Khazali, 2020, $q$ (MHNG). A. Chelicerae, posterior view. B-C. Epigyne, ventral and dorsal views. Scale bars: A $=0.2 \mathrm{~mm}$; $-\mathrm{C}=0.1 \mathrm{~mm}$.

Genus Callipelis Zamani \& Marusik, 2017

This genus is monotypic, and the female of the type species was previously unknown.

Callipelis deserticola Zamani \& Marusik, 2017

Figs 5-6

Callipelis deserticola Zamani \& Marusik, 2017: 324, fig. 5 (ठ̋).

\section{Diagnosis}

For the diagnosis of the male, see Zamani \& Marusik (2017). In the absence of any other congener, the newly described female of this species is tentatively diagnosed here by the shape of the epigynal atrium resembling an inverted droplet with narrowing posterior rims. The female of $C$. deserticola differs from those of Callilepis Westring, 1874 by their light color and distinct abdominal folium (vs dark and lacking folium) and the anterior lateral spinnerets being longer than the posterior ones (vs subequal).

\section{Material examined}

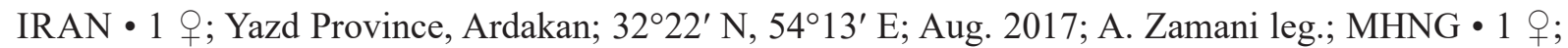

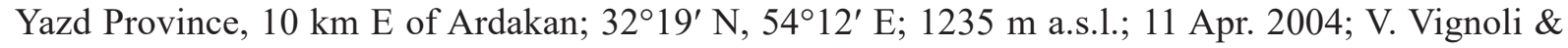
P. Crucitti leg.; SMF.

\section{Photographic record}

IRAN • 1 ㅇ; Semnan Province, Rig-e Jen; $34^{\circ} 37^{\prime}$ N, 5322' E; Nov. 2018; A. Mohajeran.

\section{Description}

\section{Female (MHNG)}

Habitus as in Figs 5A-C, 6. Total length 5.35. Carapace 2.72 long, 2.21 wide. Eye sizes and interdistance of PMEs: $\mathrm{AME}=0.18, \mathrm{ALE}=0.22, \mathrm{PME}=0.18, \mathrm{PLE}=0.22, \mathrm{PME}-\mathrm{PME}=0.12$. Carapace light yellowish brown with a dark marginal line and a distinct mark in clypeus; a distinct dark V-shaped mark in front of fovea. Sternum, maxillae and labium slightly lighter than carapace. Chelicerae (Fig. 5E) with 2 promarginal teeth and a retromarginal translucent lamina, widest at its base. Legs the same color as carapace and with numerous spines. Abdomen dorsally with long, thin setae and faded light brown stripes medially, extending into darker comb-shaped patterns laterally; ventrally without any pattern (Fig. 5D). 
Anterior lateral spinnerets cylindrical; posterior median spinnerets shorter and darker. Measurements of legs: I: 7.78 (2.30, 1.13, 1.43, 1.43, 1.49), II: 8.55 (2.30, 1.31, 1.57, 1.71, 1.66), III: 10.27 (2.54, 1.32, $1.78,2.61,2.02)$, IV: $12.07(2.99,1.45,2.23,3.18,2.22)$.

Epigyne as in Fig. 5F-J. Atrium large, inverted droplet shaped, with distinct anterior hood; copulatory openings behind lateral hoods at median part of the atrium; glands near the anterior edge of lateral hoods; copulatory ducts rather short, twisting posteriorly; receptacles not delimited from ducts, with additional bursae and glands.

\section{Male}

See Zamani \& Marusik (2017).
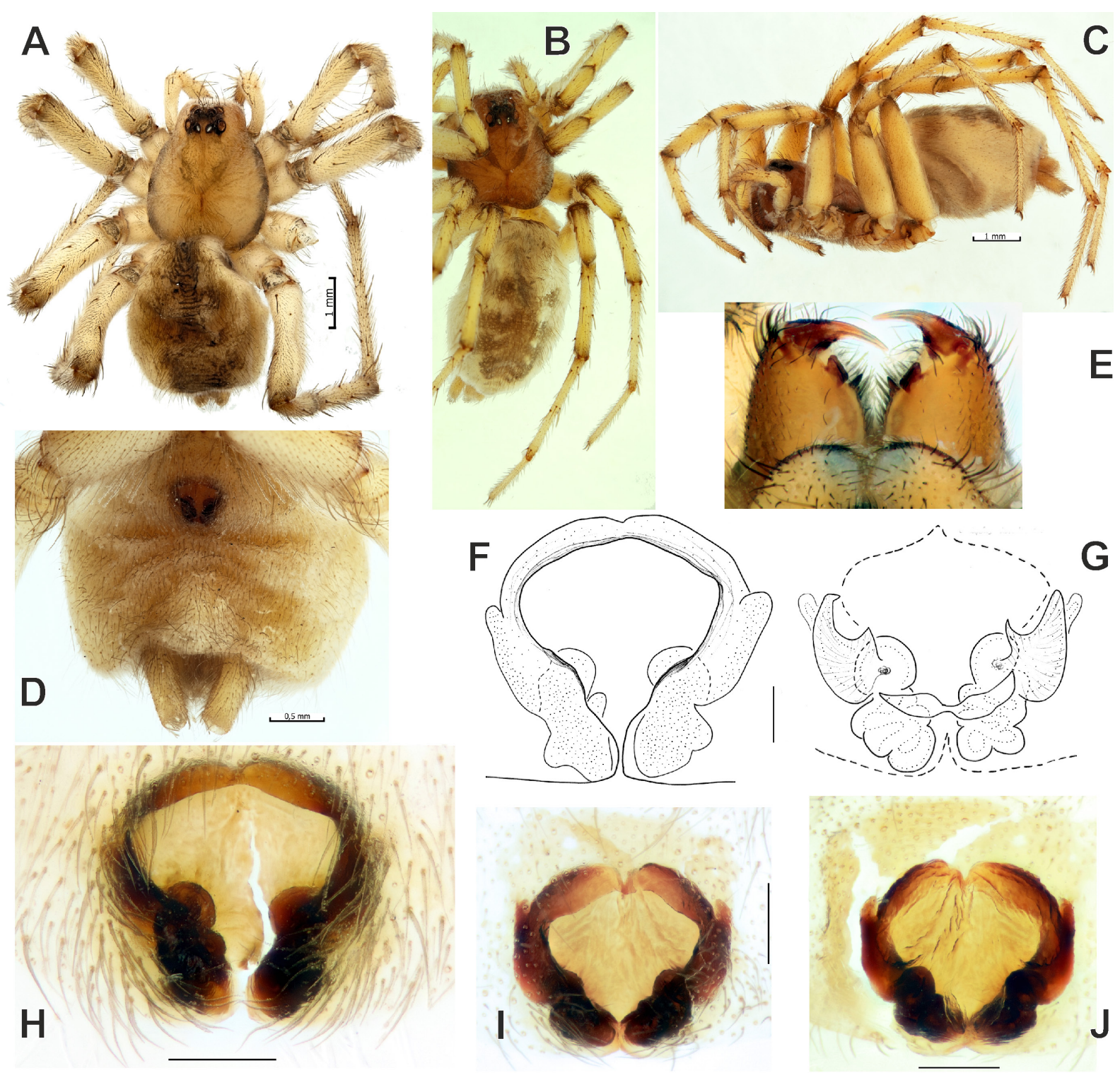

Fig. 5. Callipelis deserticola Zamani \& Marusik, 2017, $q$ (A, D-H = specimen from MHNG; B-C, I-J = specimen from SMF). A-C. Habitus, dorsal and lateral views. D. Abdomen, ventral view. E. Chelicerae, posterior view. F, H-I. Epigyne, ventral view. G, J. Epigyne, dorsal view. Scale bars: A, C=1 mm; D = $0.5 \mathrm{~mm} ; \mathrm{F}-\mathrm{G}=0.1 \mathrm{~mm} ; \mathrm{H}-\mathrm{J}=0.2 \mathrm{~mm}$. 


\section{Distribution}

Genus endemic to Iran, known from the type locality in South Khorasan Province, the newly reported locality in Yazd Province (Fig. 6B) and the photographic record (Fig. 6A) in Semnan Province, central to eastern Iran. All specimens have been observed and collected in sand dunes.
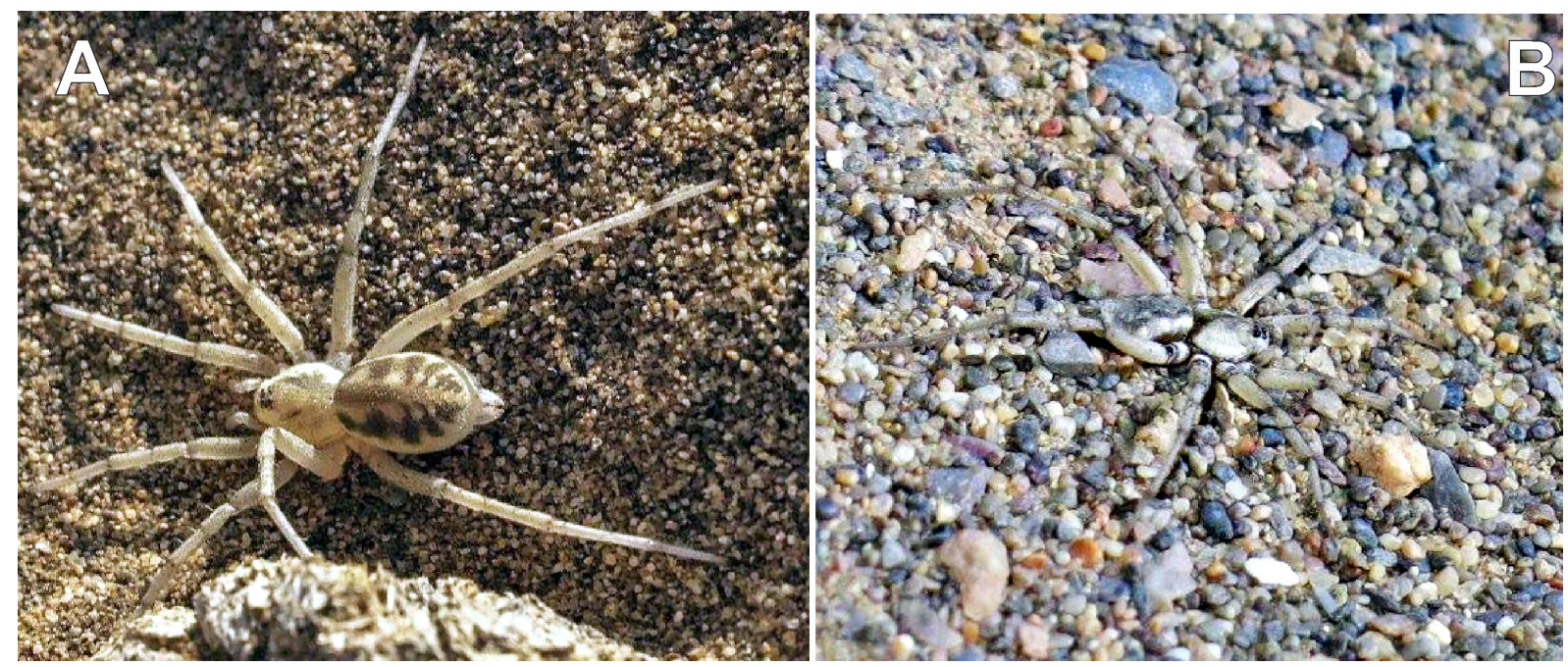

Fig. 6. Callipelis deserticola Zamani \& Marusik, 2017, + , live habitus. A. Specimen from Rig-e Jen, Semnan Province (courtesy of Ali Mohajeran). B. Specimen from Ardakan, Yazd Province (by Alireza Zamani).

Genus Cryptodrassus Miller, 1943

Cryptodrassus iranicus sp. nov. urn:1sid:zoobank.org:act:3FD0F576-4945-4079-B0BB-503412D640D5

Fig. 7

\section{Diagnosis}

The new species differs from the congeners by having a distinct tegular bulge $(T b)$ near the base of embolus.

\section{Etymology}

The specific epithet is an adjective and refers to the collection locality of the new species.

\section{Type material}

\section{Holotype}

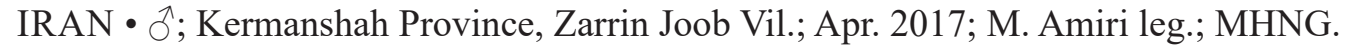

\section{Description}

\section{Male}

Habitus as in Fig. 7I. Total length 3.59. Carapace 1.57 long, 1.26 wide. Eye sizes and interdistance of PMEs: $\mathrm{AME}=0.08, \mathrm{ALE}=0.09, \mathrm{PME}=0.11, \mathrm{PLE}=0.07, \mathrm{PME}-\mathrm{PME}=0.03$. Carapace, chelicerae, sternum, maxillae and labium light reddish brown. Chelicerae (Fig. 7J) with a small promarginal tooth. 

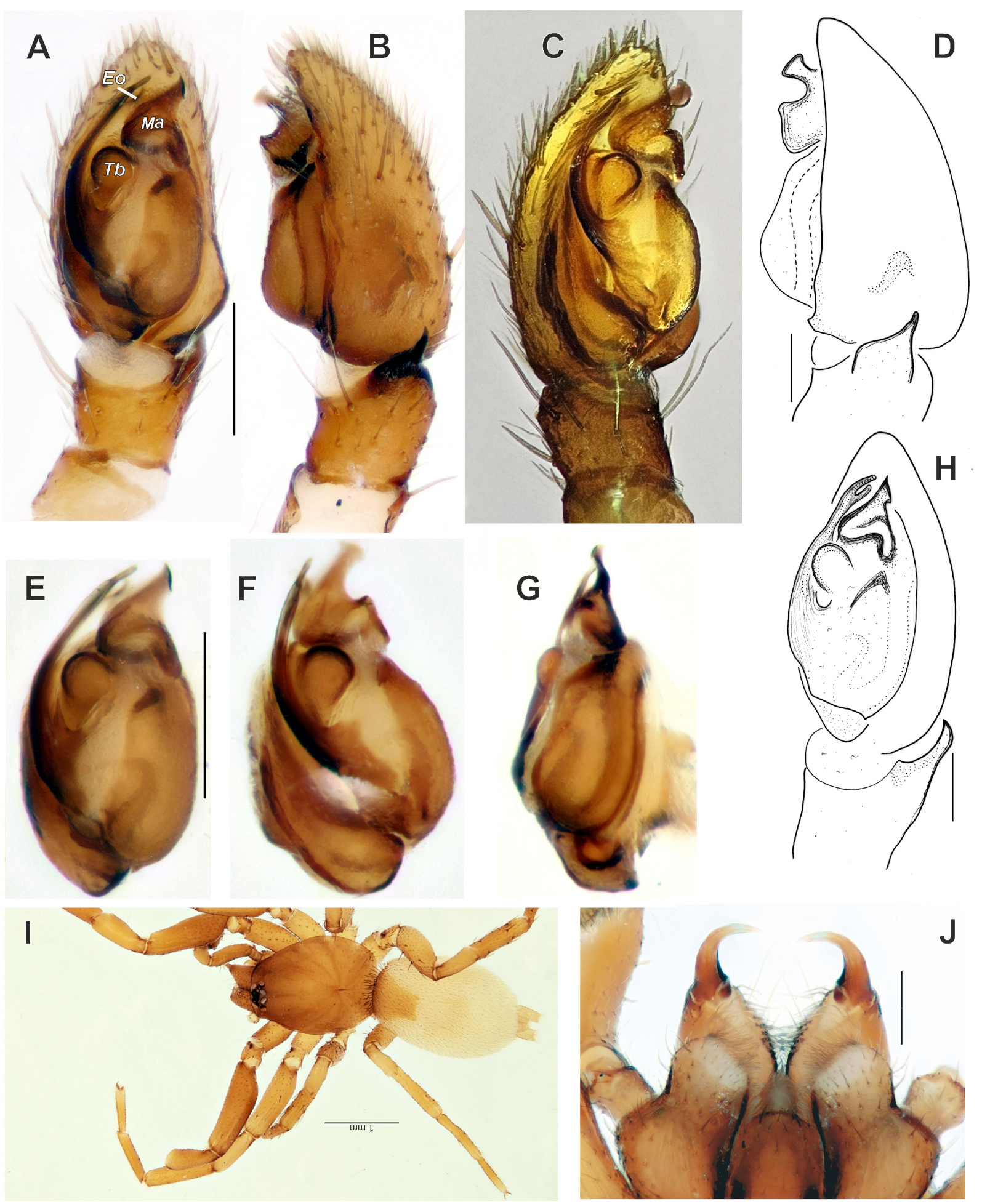

Fig. 7. Cryptodrassus iranicus sp. nov., holotype, $\hat{\partial}$ (MHNG). A, C, H. Palp, ventral, proventral and retroventral views. B, D. Palp, retrolateral view. E-G. Bulb, ventral, proventral and retroventral views. I. Habitus, dorsal view. J. Chelicerae, posterior view. Abbreviations: $E o=$ embolar outgrowth; $M a=$ median apophysis; $T b=$ tegular bulge. Scale bars: A-B, E, J = $0.2 \mathrm{~mm} ; \mathrm{D}, \mathrm{H}=0.1 \mathrm{~mm} ; \mathrm{I}=1 \mathrm{~mm}$. 
Maxillae with strong lateral protrusion. Legs the same color as carapace, with few spines and without annulations. Abdomen light brown, without any markings, with a distinct reddish brown scutum anteriorly. Spinnerets light brown and uniform in color. Measurements of legs: I: $4.78(1.35,0.79,1.18,0.85,0.61)$, II: 3.94 (1.10, 0.72, 0.93, 0.70, 0.49), III: 3.16 (0.86, 0.52, 0.62, 0.69, 0.47), IV: 4.52 (1.19, 0.69, 0.98, $1.04,0.62)$.

Palp as in Fig. 7A-H. Femur and patella unmodified; tibial apophysis small, sharply pointed, shorter than tibia; cymbium with rounded and short tip; bulb elongate oval; tegulum with antero-prolateral bulge $(T b)$ near base of embolus; median apophysis $(\mathrm{Ma})$ (or conductor sensu Chatzaki et al. 2002 and Chatzaki 2018) subtriangular in ventral view, lacking hook; embolus relatively short, filiform, originating at ca 8 o'clock position and terminating at about 12 , terminal part with short, spine-like outgrowth (Eo).

\section{Female}

Unknown.

\section{Distribution}

Known only from the type locality in Kermanshah Province, western Iran.

Genus Drassodes Westring, 1851

Drassodes persianus sp. nov. urn:1sid:zoobank.org:act:8A053277-FFE1-4212-B591-51C370E1DCE6

Fig. 8A-F

\section{Diagnosis}

The epigyne of the new species is most similar to that of D. longispinus Marusik \& Logunov, 1995 (Fig. 8G-H) but can be distinguished by the rounded posterior margin of the median plate being slightly extended beyond the epigastric furrow (vs straight, not extended), the relatively long atrium (width/length ratio as shown by broken lines ca $1.4 \mathrm{vs} 2$ ) and the lateral margins $(\mathrm{Lm}) \mathrm{S}$-shaped with lateral indentations (vs almost parallel).

\section{Etymology}

The specific epithet is an adjective and refers to the historical region of the Middle East, located in eastern Mesopotamia, which is now Iran.

\section{Type material}

\section{Holotype}

IRAN • \%; Sistan \& Baluchistan Province, Khash, surroundings of Taftan volcano; $28^{\circ} 36^{\prime} \mathrm{N}, 61^{\circ} 07^{\prime} \mathrm{E}$; May 2018; A. Zamani leg.; MHNG.

\section{Other material examined}

IRAN • 1 (epigyne only, body lost); Kermanshah Province, Zarrin Joob Vil.; Apr. 2017; M. Amiri leg.; PSU.

\section{Comparative material examined}

Drassodes longispinus Marusik \& Logunov, 1995

RUSSIA 1 1 ; Orenburg Area, Belyaevka Distr., 'Burtinskaya Steppe' division of Orenburg Reserve; 5122' N, 5559' E; Aug. 2016; V.A. Nemkov leg.; PSU-8263. 


\section{Description}

Female (holotype)

Habitus as in Fig. 8A. Total length 9.65. Carapace 3.83 long, 3.10 wide. Eye sizes and interdistances of AMEs and PMEs: $\mathrm{AME}=0.19, \mathrm{ALE}=0.17, \mathrm{PME}=0.16, \mathrm{PLE}=0.17, \mathrm{AME}-\mathrm{AME}=0.13, \mathrm{PME}-\mathrm{PME}=$ 0.16. Carapace brown, darker in pars cephalica. Chelicerae, maxillae and labium dark reddish brown. Chelicera (Fig. 8B) with 3 retromarginal teeth. Sternum light yellowish brown, darker in the margins. Legs light yellowish brown and without annulations. Abdomen dark gray, without any pattern. Spinnerets light gray. Measurements of legs: I: 10.80 (3.10, 1.48, 2.55, 2.22, 1.45), II: 10.83 (2.91, 1.65, 2.44, 2.27, 1.56), III: 9.76 (2.75, 1.16, 2.16, 2.17, 1.52), IV: $13.31(3.45,1.56,3.00,3.70,1.60)$.

Epigyne as in Fig. 8C-F. Atrium 1.4 times as wide as long, lateral margins inclined mesally, S-shaped with lateral indentations, posterior margin rounded, slightly extended beyond epigastric furrow; mesal receptacles ca 1.2 times wider than lateral ones.
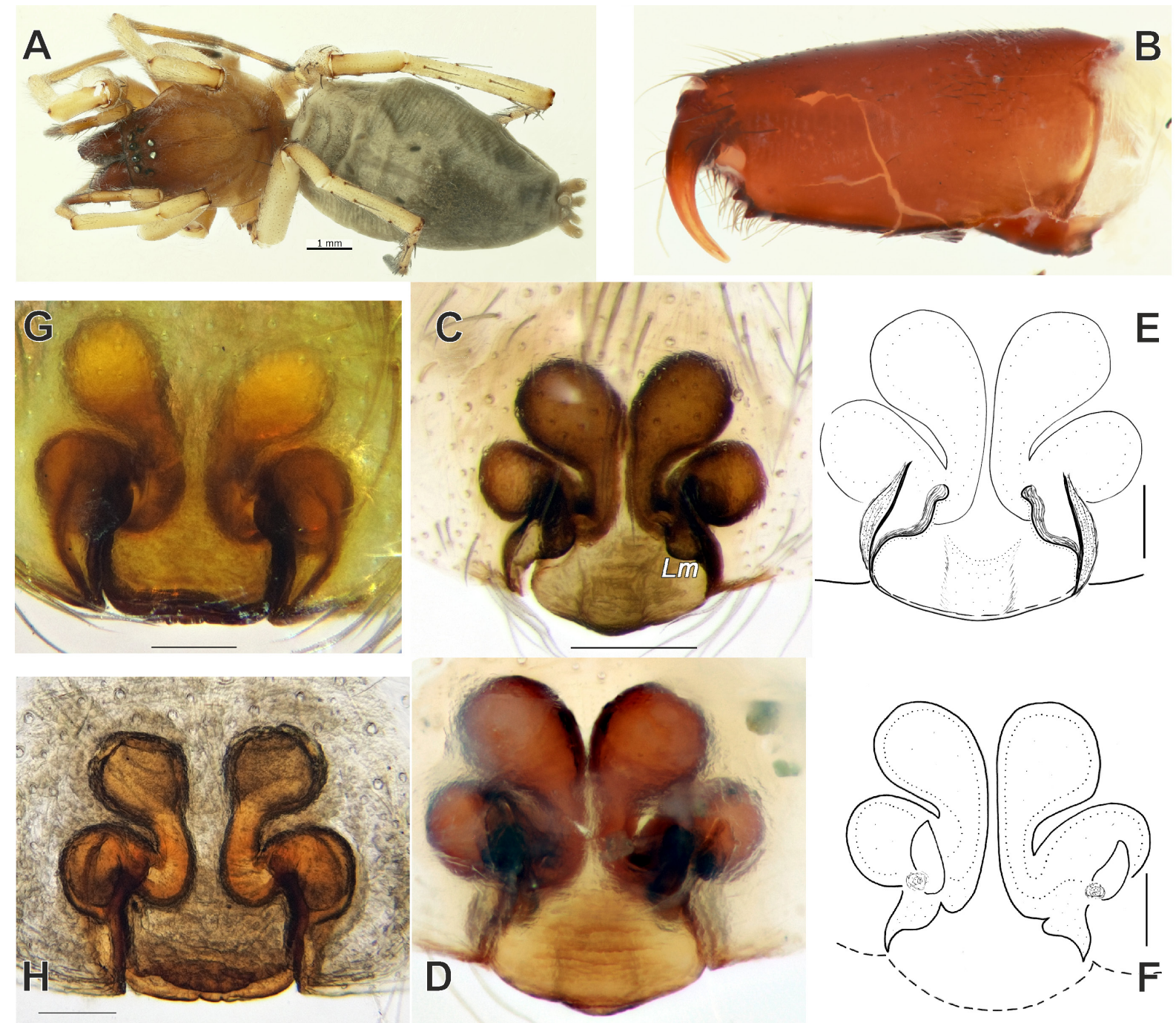

Fig. 8. A-F. Drassodes persianus sp. nov., holotype, + (MHNG). A. Habitus, dorsal view. B. Chelicera, prolateral view. C, E. Epigyne, ventral view. D, F. Epigyne, dorsal view. - G-H. D. longispinus Marusik \& Logunov, 1995, ( (PSU-8263). G. Epigyne, ventral view. H. Epigyne, dorsal view. Abbreviation: Lm= lateral margin. Scale bars: $A=1 \mathrm{~mm} ; \mathrm{C}=0.2 \mathrm{~mm} ; \mathrm{E}-\mathrm{H}=0.1 \mathrm{~mm}$. 


\section{Male \\ Unknown.}

\section{Distribution}

Known only from the type locality in Sistan \& Baluchistan Province, southeastern Iran, and another locality in Kermanshah Province, western Iran.

Genus Echemus Simon, 1878

Echemus caspicus sp. nov. urn:lsid:zoobank.org:act:CFBF122D-F516-4D05-B4F9-85AD591F4511

Fig. 9

\section{Diagnosis}

The new species is most similar to the generotype E. angustifrons (Westring, 1861) by having an S-shaped septum (rather than rectangular as in, e.g., E. kaltsasi Chatzaki, 2019 and E. levyi Kovblyuk \& Seyyar, 2009) but differs by the much narrower anterior part (or stalk), giving a bell-shaped form to the septum (widened part of septum/stalk of stem ratio $>2$, vs $<1.5$ in E. angustifrons, cf. Fig. 9B and Chatzaki \& Van Keer 2019: fig. 9). Also, the anterior epigynal margin is equally sclerotized, round and reaches the lateral sides of the plate in the new species (vs extending anteriorly and forming a triangular sclerotization in E. angustifrons).

\section{Etymology}

The specific epithet is an adjective and refers to the Caspian region, in which the type locality of the new species in located.

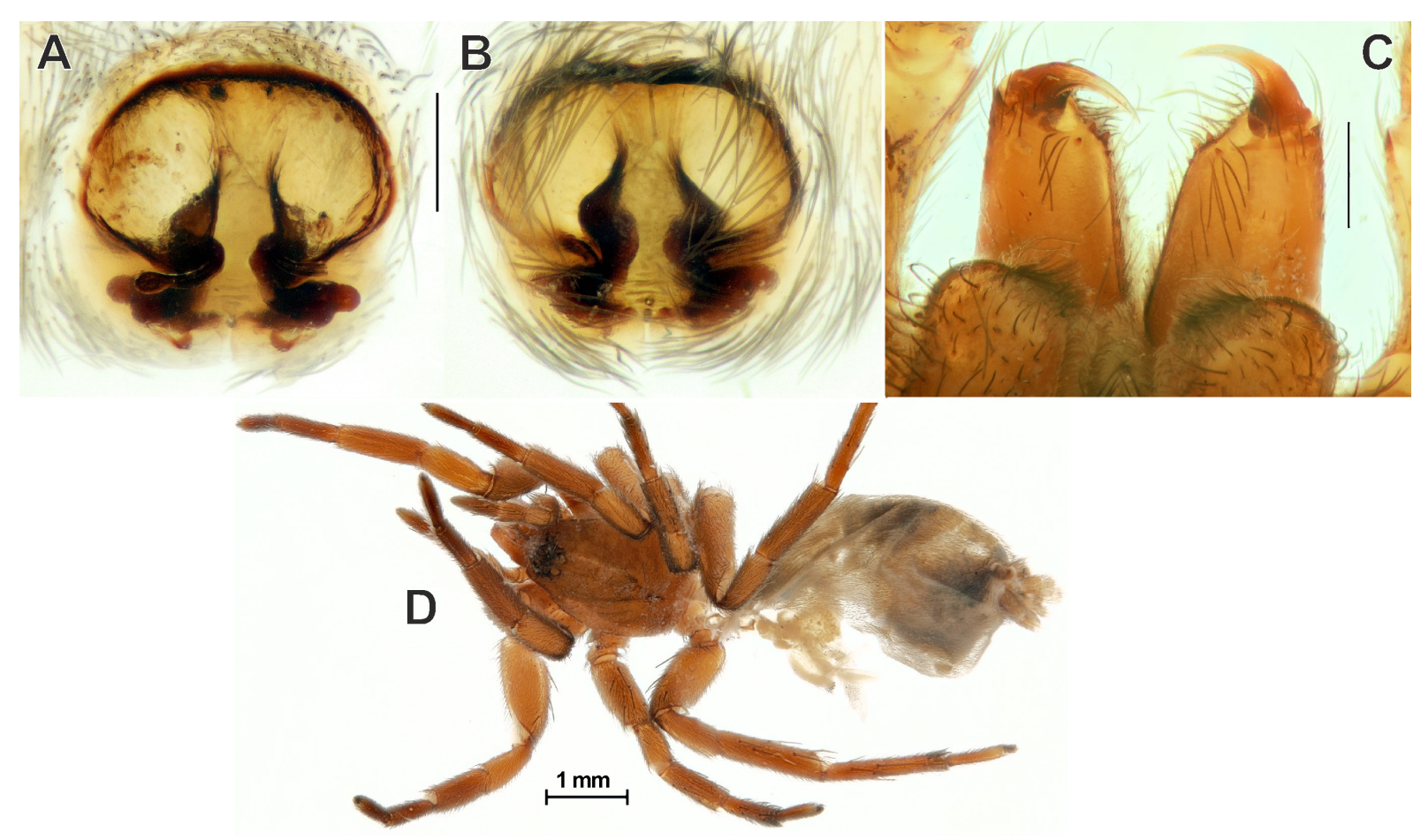

Fig. 9. Echemus caspicus sp. nov., holotype, $q$ (MHNG). A-B. Epigyne, dorsal and ventral views. C. Chelicerae, posterior view. D. Habitus, dorsal view. Scale bars: $0.2 \mathrm{~mm}$, unless stated otherwise. 


\title{
Type material
}

\section{Holotype}

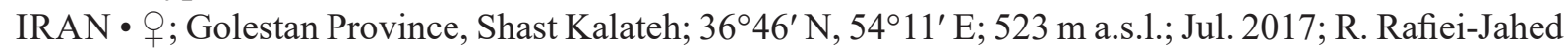
leg.; MHNG.

\section{Description}

Female

Habitus as in Fig. 9D. Total length 5.29. Carapace 1.87 long, 1.26 wide. Eye sizes and interdistance of PMEs: $\mathrm{AME}=0.14, \mathrm{ALE}=0.13, \mathrm{PME}=0.12, \mathrm{PLE}=0.11, \mathrm{PME}-\mathrm{PME}=0.07$. Carapace, sternum, labium, chelicerae and maxillae dark brown, without any pattern. Chelicerae (Fig. 9C) with 3 pro- and 1 retromarginal teeth. Legs the same color as carapace, without annulations. Abdomen and spinnerets gray, without any pattern. Spinnerets uniform in color and slightly lighter in the apical segment. Measurements of legs: I: 4.59 (1.34, 0.91, 0.98, 0.76, 0.60), II: 4.26 (1.31, 0.83, 0.93, 0.66, 0.53), III: 4.04 (1.12, 0.73, $0.76,0.78,0.65)$, IV: $5.48(1.47,0.86,1.11,1.35,0.69)$.

Epigyne as in Fig. 9A-B. Atrium large (ca 1.8 times as wide as long), wider than epigynal plate's length, lateral margins distinct; septum thin, stalk 4.6 times thinner than atrium's width; accessorial gland transverse and as long as receptacles, parallel to copulatory ducts; copulatory ducts transverse, moderately coiled, connected to oval receptacles posteriorly and to accessorial glands.

\section{Male \\ Unknown.}

\section{Distribution}

Known only from the type locality in Golestan Province, northern Iran. This is the first record of the genus Echemus in Iran.

\author{
Genus Gnaphosa Latreille, 1804
}

Gnaphosa qamsarica sp. nov. urn:1sid:zoobank.org:act:571ED6FD-935D-4527-8581-FEBD31C996E5

Fig. 10

\section{Diagnosis}

The new species differs from all Palearctic congeners by the widely separated lateral margins not converging posteriorly, and widely separated receptacles leaving an open atrium with parallel rims (vs receptacles almost touching and lateral margins converging posteriorly). Furthermore, it differs by the presence of short copulatory ducts, almost vertical and in line with the receptacles (vs bent copulatory ducts parallel to the receptacles). The species most similar to G. qamsarica sp. nov. are: G. cumensis Ponomarev, 1981, G. halophila Esyunin \& Efimik, 1997, G. jucunda Thorell, 1875, G. saurica Ovtsharenko, Platnick \& Song, 1992, G. ukrainica Ovtsharenko, Platnick \& Song, 1992 and G. zeugitana Pavesi, 1880. The last one is the most similar in that the copulatory ducts are almost in line with the receptacles and the receptacles are widely separated. However, G. qamsarica sp. nov. differs from G. zeugitana by the parallel lateral margins and the rectangular atrium (vs triangular).

\section{Etymology}

The specific epithet is an adjective and refers to the type locality of the new species. 


\section{Type material}

\section{Holotype}

IRAN • O Isfahan Province, Qamsar \& Barzok Protected Area, $55 \mathrm{~km} \mathrm{SW}$ of Qamsar, $14 \mathrm{~km}$ NE of Kamoo, near the road of Gargash observatory; $33^{\circ} 37^{\prime}$ N, $51^{\circ} 19^{\prime}$ E; 2710 m a.s.1.; 19 May 2016; P. Ponel leg.; MHNG.

\section{Description}

\section{Female}

Habitus as in Fig. 10H. Total length 4.78. Carapace 1.79 long, 1.45 wide. Eye sizes and interdistance of PMEs: $\mathrm{AME}=0.07, \mathrm{ALE}=0.09, \mathrm{PME}=0.09, \mathrm{PLE}=0.08, \mathrm{PME}-\mathrm{PME}=0.04$. Carapace, chelicerae, sternum, maxillae and labium dark brown; carapace with a distinct V-shaped mark, separating pars cephalica from pars thoracica. Chelicerae (Fig. 10G) with 2 promarginal teeth and a serrated bifurcate retromarginal keel. Legs lighter than carapace, with few spines. Abdomen light brown, without any markings. Spinnerets light brown and uniform in color. Measurements of legs: I: 4.29 (1.15, 0.73, 0.96, 0.74, 0.71), II: 4.13 (1.12, 0.72, 0.85, 0.73, 0.71), III: 3.60 (0.98, 0.57, 0.65, 0.78, 0.62), IV: 5.40 (1.39, $0.79,1.08,1.26,0.88)$.

Epigyne as in Fig. 10A-F. Atrium rectangular; lateral margins $(\mathrm{Lm})$ parallel, as long as scape; copulatory ducts almost as broad as receptacles, parallel to each other (i.e., almost vertical); receptacles oval and in line with copulatory ducts, separated by one receptacle width; glands indistinct.

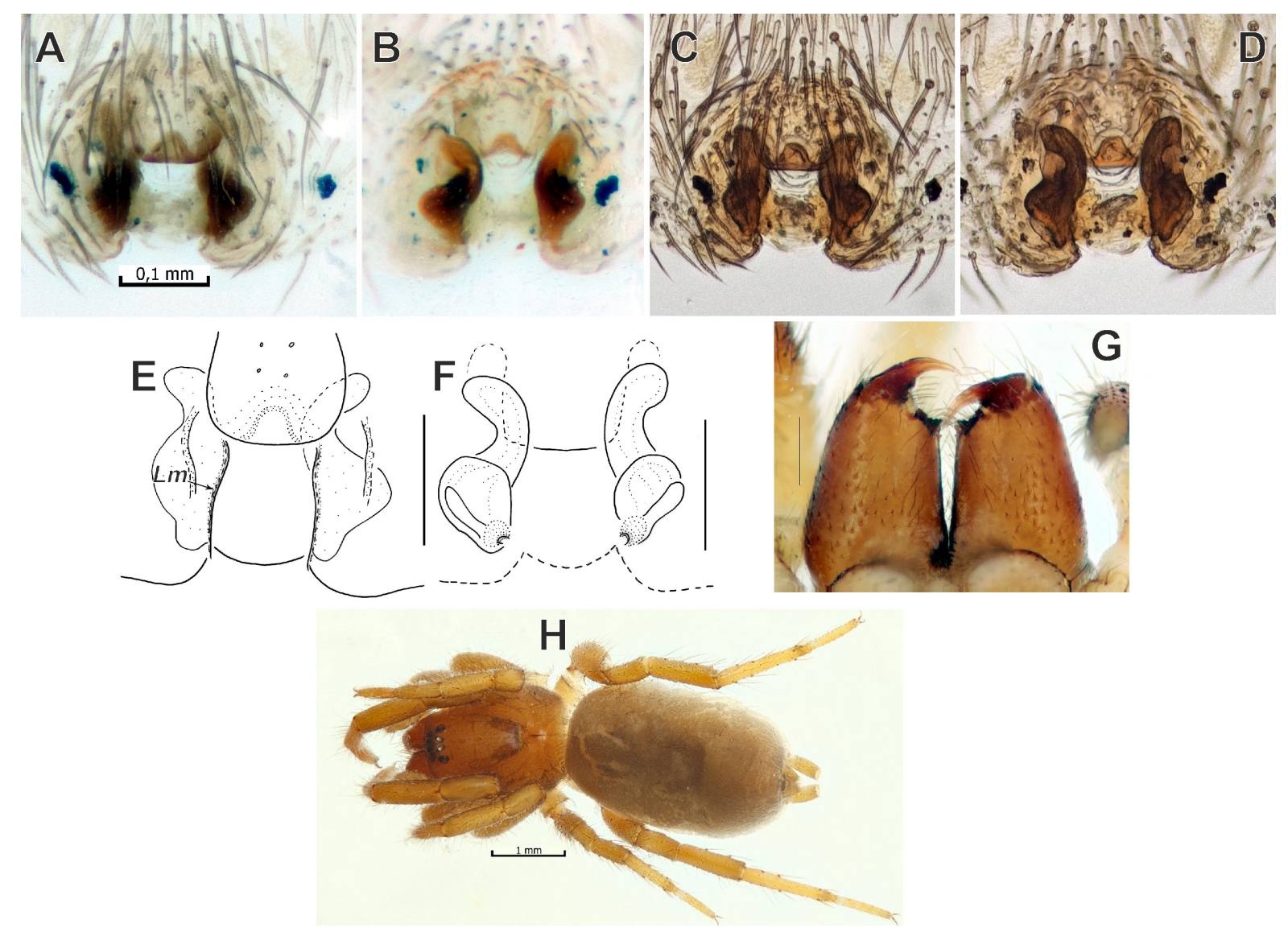

Fig. 10. Gnaphosa qamsarica sp. nov., holotype, $q$ (MHNG). A, C, E. Epigyne, ventral view. B, D, F. Epigyne, dorsal view. G. Chelicerae, posterior view. H. Habitus, dorsal view. Abbreviation: $L m=$ lateral margin. Scale bars: $0.1 \mathrm{~mm}$, unless stated otherwise. 


\section{Male \\ Unknown. \\ Distribution}

Known only from the type locality in Isfahan Province, central Iran.

Genus Haplodrassus Chamberlin, 1922

Haplodrassus medes sp. nov. urn:1sid:zoobank.org:act:22DDED83-4DA5-4746-8585-F28B0D1A0708

Fig. 11

\section{Diagnosis}

The new species is similar to H. bohemicus Miller \& Buchar, 1977, H. concertor (Simon, 1878), H. securifer Bosmans \& Abrous, 2018, H. pseudosignifer Marusik, Hippa \& Koponen, 1996 and H. aenus Thaler, 1984 by having a relatively thin embolic apophysis $(E a)$ with smooth surface/edges and by being over 2.5 times as long as wide but differs from them by having a prolateral bulge on the bulb $(B b$, Fig. 11B, E), and by the shape of the tibial apophysis, relatively sharp and straight (vs with indentations or sharper).

\section{Etymology}

The specific epithet is a noun in apposition and refers to the ancient group of Iranian people who inhabited an area known as Media between western and northern Iran.

\section{Type material}

\section{Holotype}

IRAN - $\mathrm{O}^{\prime}$; Fars Province, around Ghaderabad; $30^{\circ} 22^{\prime}$ N, 53ำ18' E; 11 Jun. 1974; A. Senglet leg.; MHNG.

\section{Description}

\section{Male}

Habitus as in Fig. 11A. Total length 6.56. Carapace 3.40 long, 2.54 wide. Eye sizes and interdistance of PMEs: $\mathrm{AME}=0.16, \mathrm{ALE}=0.15, \mathrm{PME}=0.19, \mathrm{PLE}=0.12, \mathrm{PME}-\mathrm{PME}=0.05$. Carapace dark reddish brown, slightly lighter in pars thoracica, with fade radiating lines from atrium to submarginal area. Chelicerae, maxillae and labium dark brown. Chelicerae (Fig. 11J) with 2 pro- and 2 retromarginal teeth. Sternum light brown, slightly darker anteriorly. Legs light yellowish, without annulations. Abdomen light brown, without any markings. Spinnerets light gray and uniform in color. Measurements of legs: I: 8.99 (2.42, 1.54, 2.13, 1.59, 1.31), II: 7.94 (2.15, 1.26, 1.84, 1.48, 1.21), III: 6.92 (1.87, 1.02, 1.37, 1.60, 1.06), IV: $9.48(2.75,1.33,1.80,2.22,1.38)$.

Palp as in Fig. 11B-I. Tibial apophysis as long as tibia with subparallel sides and almost rounded tip; embolic division with prolateral bulge $(B b)$ formed at the prolateral base of the embolic division; embolic apophysis $(E a)$ straight, arrow-like, with distinct straight ridge and subtriangular tip, relatively thin, ca 2.6 times as long as wide; embolus distinct, widening terminally, with two very pointed tips, one retrolateral and one dorsal.

\section{Female}

Unknown.

\section{Distribution}

Known only from the type locality in Fars Province, southcentral Iran. 


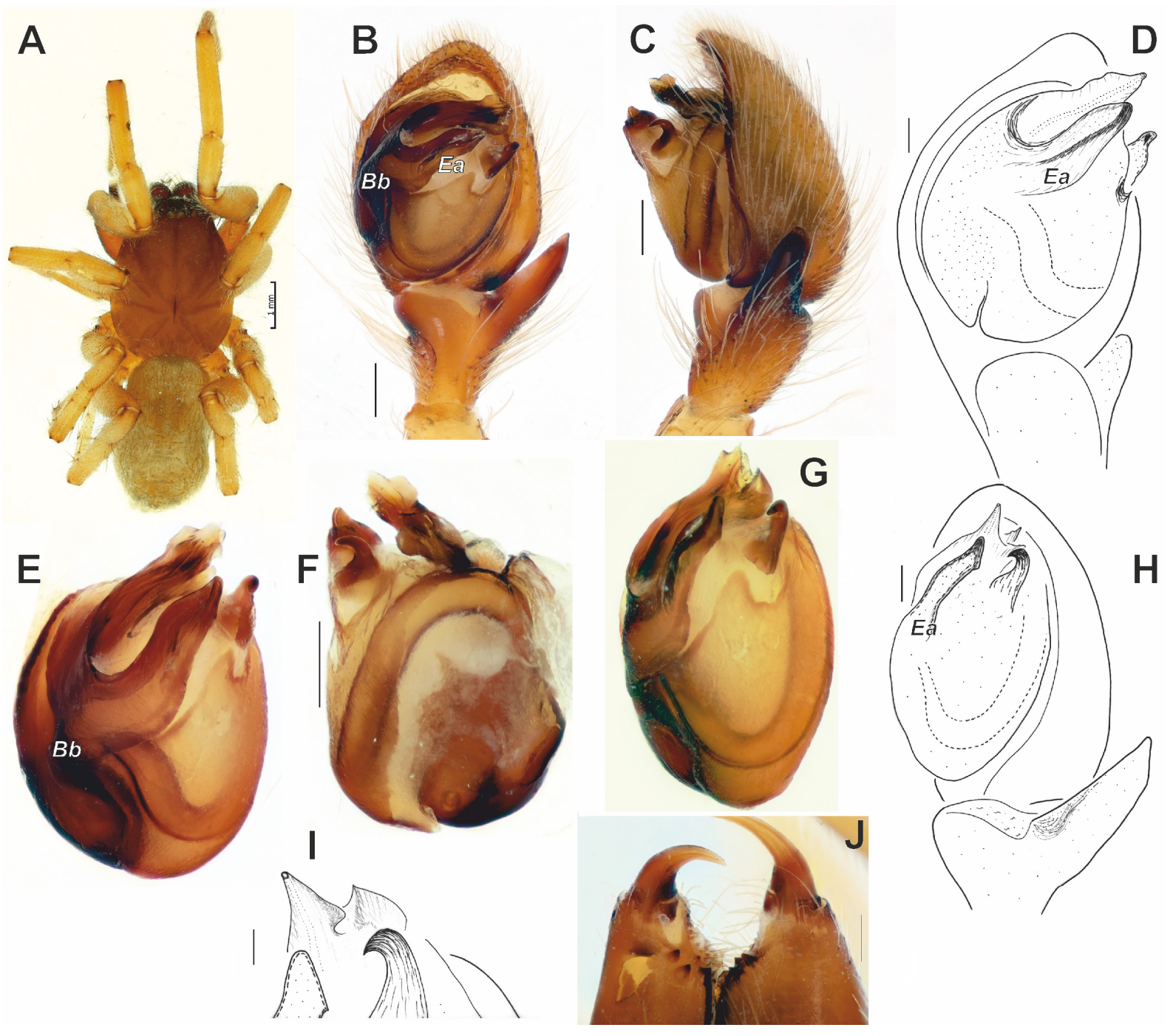

Fig. 11. Haplodrassus medes sp. nov., holotype, ô (MHNG). A. Habitus, dorsal view. B-D, H. Palp, ventral, retrolateral, proventral and retroventral views. E-G. Bulb, proventral, dorsal and retroventral views. I. Apical portion of bulb, retroventral view. J. Chelicerae, posterior view. Abbreviations: $B b=$ bulge of bulb; $E a=$ embolic apophysis. Scale bars: A $=1 \mathrm{~mm}$; B-C, F, J $=0.2 \mathrm{~mm}$; D, H-I $=0.1 \mathrm{~mm}$.

Haplodrassus qashqai sp. nov.

urn:1sid:zoobank.org:act:0EE16C9F-6CC6-4AF4-8343-750215C9FBD6

Figs $12-14$

\section{Diagnosis}

The new species differs from other males (H. dalmatensis (L. Koch, 1866), H. omissus (O. PickardCambridge, 1872), H. orientalis (L. Koch, 1866), H. rufipes (Lucas, 1846), H. securifer Bosmans \& Abrous, 2018) that have one or two pointed teeth on the embolic apophysis and/or have the indented tibial apophysis by a combination of a largely serrated inner surface of the embolic apophysis and a tibial 
apophysis with a single pointed tip. Females of the new species resemble those of $H$. pseudosignifer Marusik, Hippa \& Koponen, 1996, H. typhon (Simon, 1878), H. invalidus (O. Pickard-Cambridge, 1872) and H. concertor (Simon, 1878) in having the epigynal plate with almost parallel margins and conical posterior ends but differ by the presence of distinct longitudinal folds along the spermathecal sacs (vs bell-shaped in all others).

\section{Etymology}

The specific epithet is a noun in apposition, referring to a conglomeration of clans in Iran consisting of mostly Turkic peoples but also Lurs, Kurds and Arabs.

\section{Type material}

\section{Holotype}

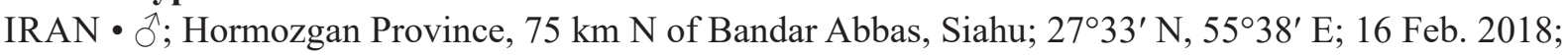
A. Zamani leg.; MHNG.
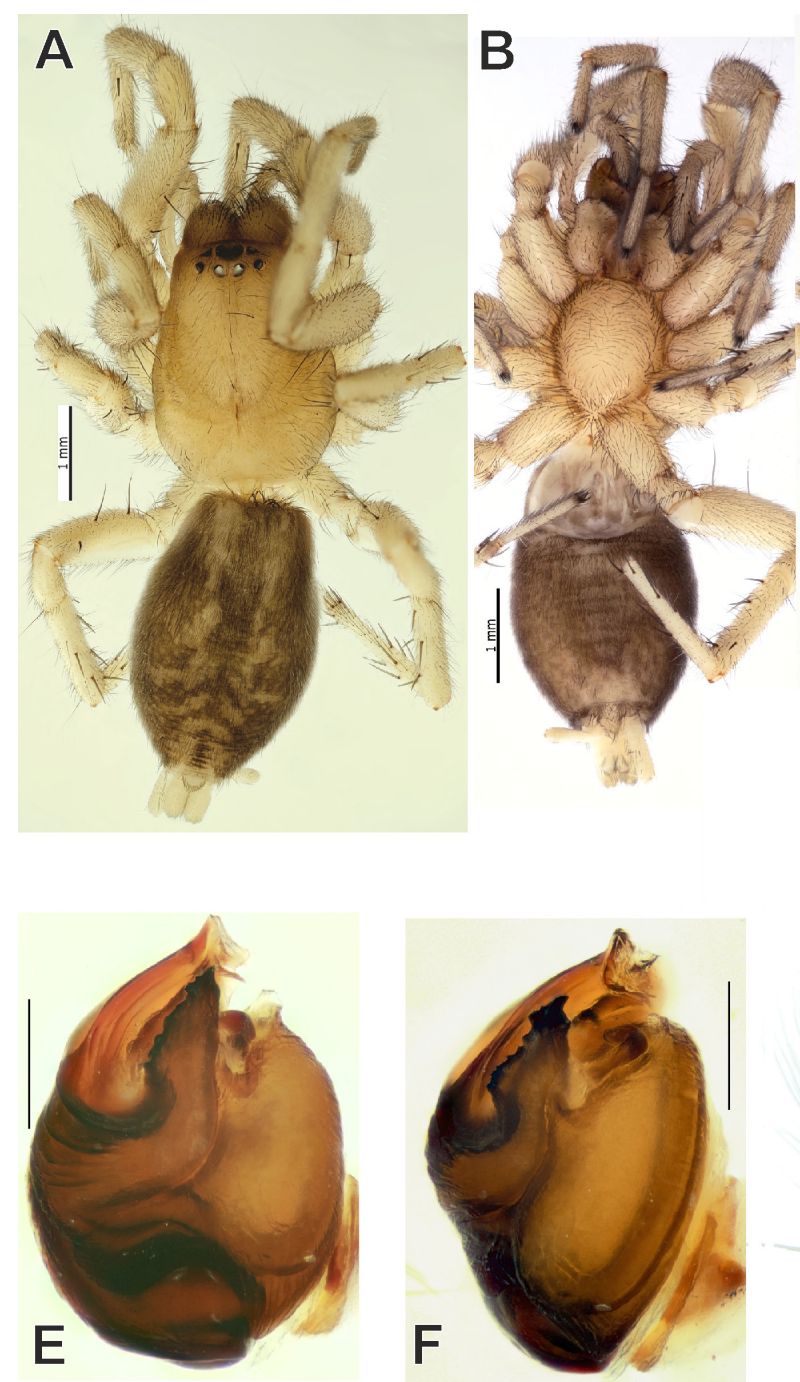
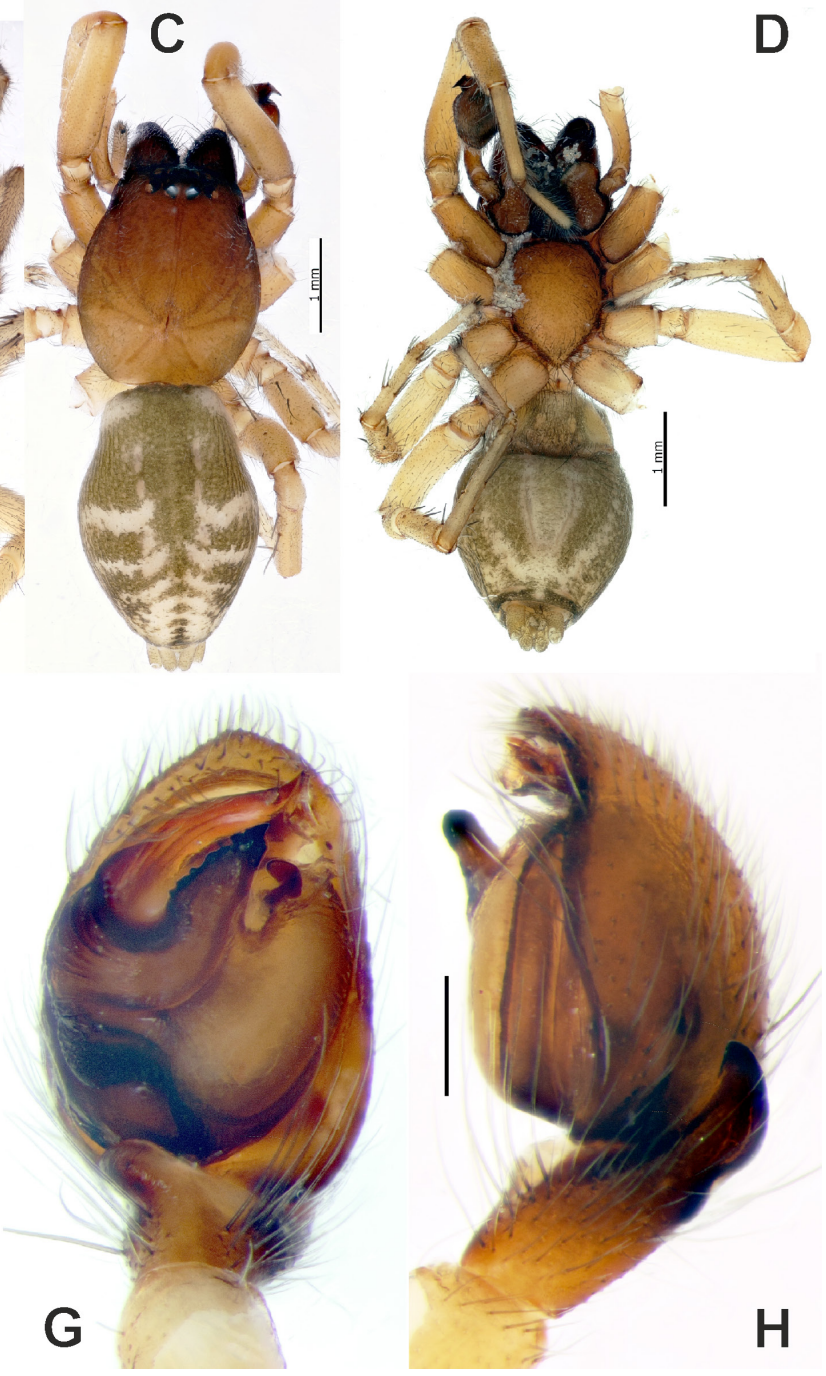

Fig. 12. Haplodrassus qashqai sp. nov. $(\mathrm{A}-\mathrm{B}=$ paratype, $q$ from Lorestan Province, $\mathrm{MHNG} ; \mathrm{C}-\mathrm{H}=$ holotype, ô, MHNG). A, C. Habitus, dorsal view. B, D. Habitus, ventral view. E-F. Bulb, ventral and proventral views. G-H. Palp, ventral and retrolateral views. Scale bars: $0.2 \mathrm{~mm}$, unless stated otherwise. 


\section{Paratypes}

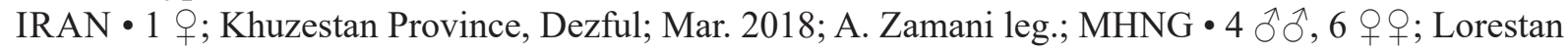
Province, Pol-e Dokhtar; Apr. 2017; A. Zamani leg.; MHNG.

\section{Description}

\section{Male (holotype)}

Habitus as in Fig. 12C-D. Total length 5.00. Carapace 2.26 long, 1.87 wide. Eye sizes and interdistance of PMEs: $\mathrm{AME}=0.13, \mathrm{ALE}=0.15, \mathrm{PME}=0.14, \mathrm{PLE}=0.10, \mathrm{PME}-\mathrm{PME}=0.08$. Carapace dark brown, lighter in pars thoracica, with faded radiating lines from fovea to submarginal area. Chelicerae, maxillae and labium dark brown. Sternum light brown, slightly darker anteriorly. Chelicera with 2 pro- and 2 retromarginal teeth. Legs light yellowish and without annulations. Abdomen dorsally dark gray, with numerous transverse light bands, forming a patch posteriorly, ventrally with distinct tracheal marks and a V-shaped light pattern surrounding them. Spinnerets light gray and uniform in color. Measurements of legs: I: 6.19 (1.76, 1.00, 1.42, 1.16, 0.85), II missing, III: 4.74 (1.32, 0.68, 0.91, 1.02, 0.81), IV: 6.82 $(1.82,0.96,1.47,1.60,0.97)$.

Palp as in Figs 12E-H, 13A-D, 14A-C. Tibial apophysis as long as tibia, paddle-shaped, angled dorsally, with a pointed tip; embolic apophysis with distinctly serrated inner surface; embolus with wide, blunt end and with an additional pointed outgrowth that arises from its base.

Female (paratype, Lorestan Province)

Habitus as in Figs 12A-B. Total length 5.49. Carapace 2.54 long, 1.93 wide. Eye sizes and interdistance of PMEs: $\mathrm{AME}=0.09, \mathrm{ALE}=0.14, \mathrm{PME}=0.15, \mathrm{PLE}=0.09, \mathrm{PME}-\mathrm{PME}=0.05$. Carapace, chelicerae, maxillae, labium and sternum light yellowish brown. Chelicera with 3 pro- and 2 retromarginal teeth.
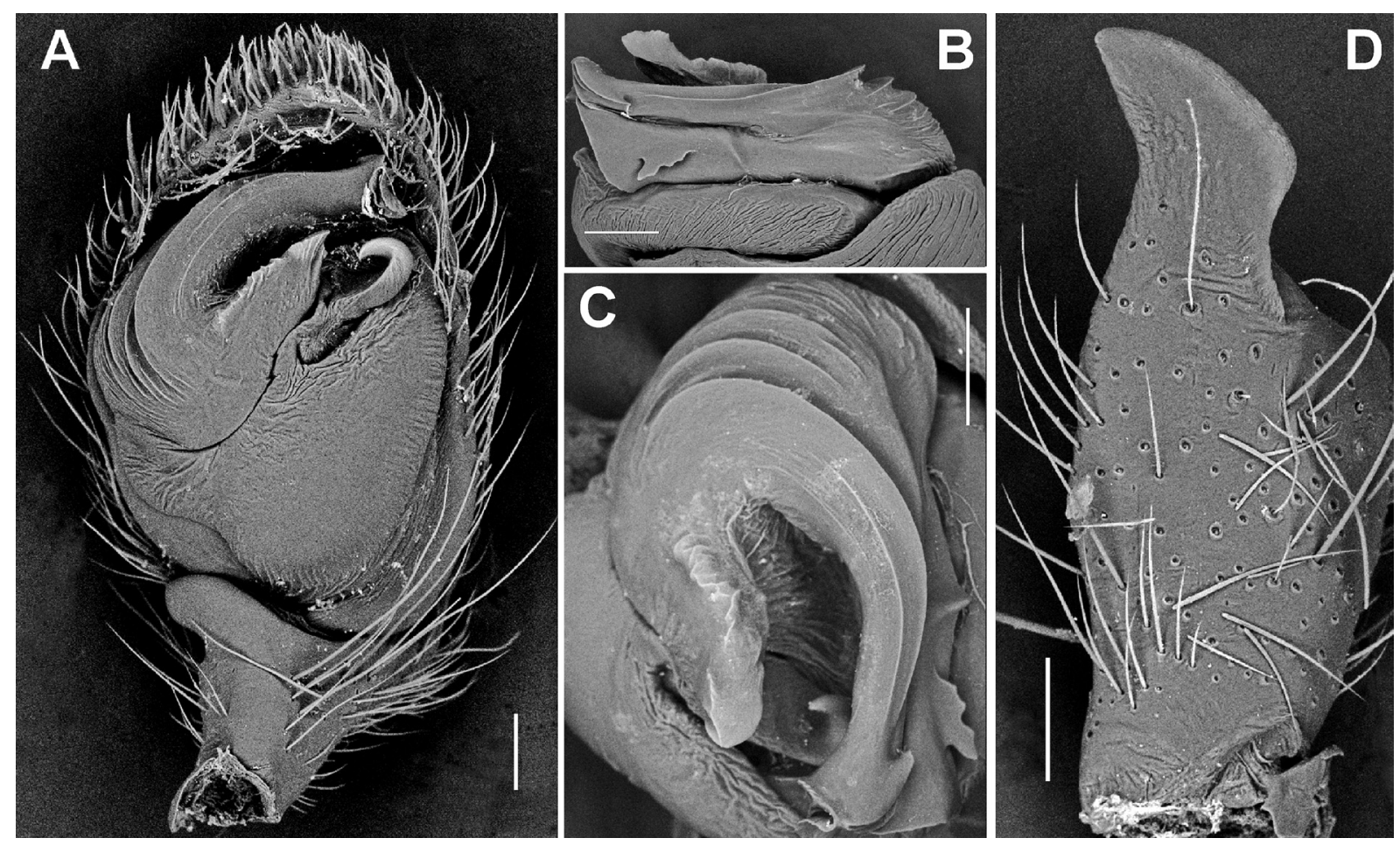

Fig. 13. Haplodrassus qashqai sp. nov., paratype, $\widehat{\jmath}$ from Lorestan Province (MHNG), SEM graphs of the male palp. A. Ventral view. B. Embolus, dorsal view. C. Apical portion of bulb. D. Tibial apophysis, retrolateral view. Scale bars: $0.1 \mathrm{~mm}$. 
Legs light gray and without annulations. Abdomen dorsally dark gray, with two longitudinal light gray bands leading to numerous transverse light bands, ventrally with a light gray patch posteriorly. Spinnerets light gray and uniform in color. Measurements of legs: I: 6.74 (1.97, 1.13, 1.55, 1.24, 0.85), II: 5.99 (1.76, 1.01, 1.28, 1.04, 0.90), III: 5.24 (1.55, 0.78, 0.98, 1.07, 0.86), IV: 7.41 (2.05, 1.08, 1.67, 1.79, 0.82).

Epigyne as in Fig. 14D-H. Epigynal plate about 1.3 times as long as wide, with weakly sclerotized anterior margin; atrium long and thin, almost 2 times as long as wide and $1 / 3$ of epigynal plate width, with parallel lateral margins converging posteriorly and lateral sclerotization at anterior half; receptacles round, as wide as the narrowest part of the atrium; fertilization ducts long; distinct anterior bursae present with longitudinal folds; lateral anterior glandular heads at outer edges of the bursae.

\section{Distribution}

Known from the listed localities in Hormozgan, Khuzestan and Lorestan Provinces, southwestern to southern Iran.

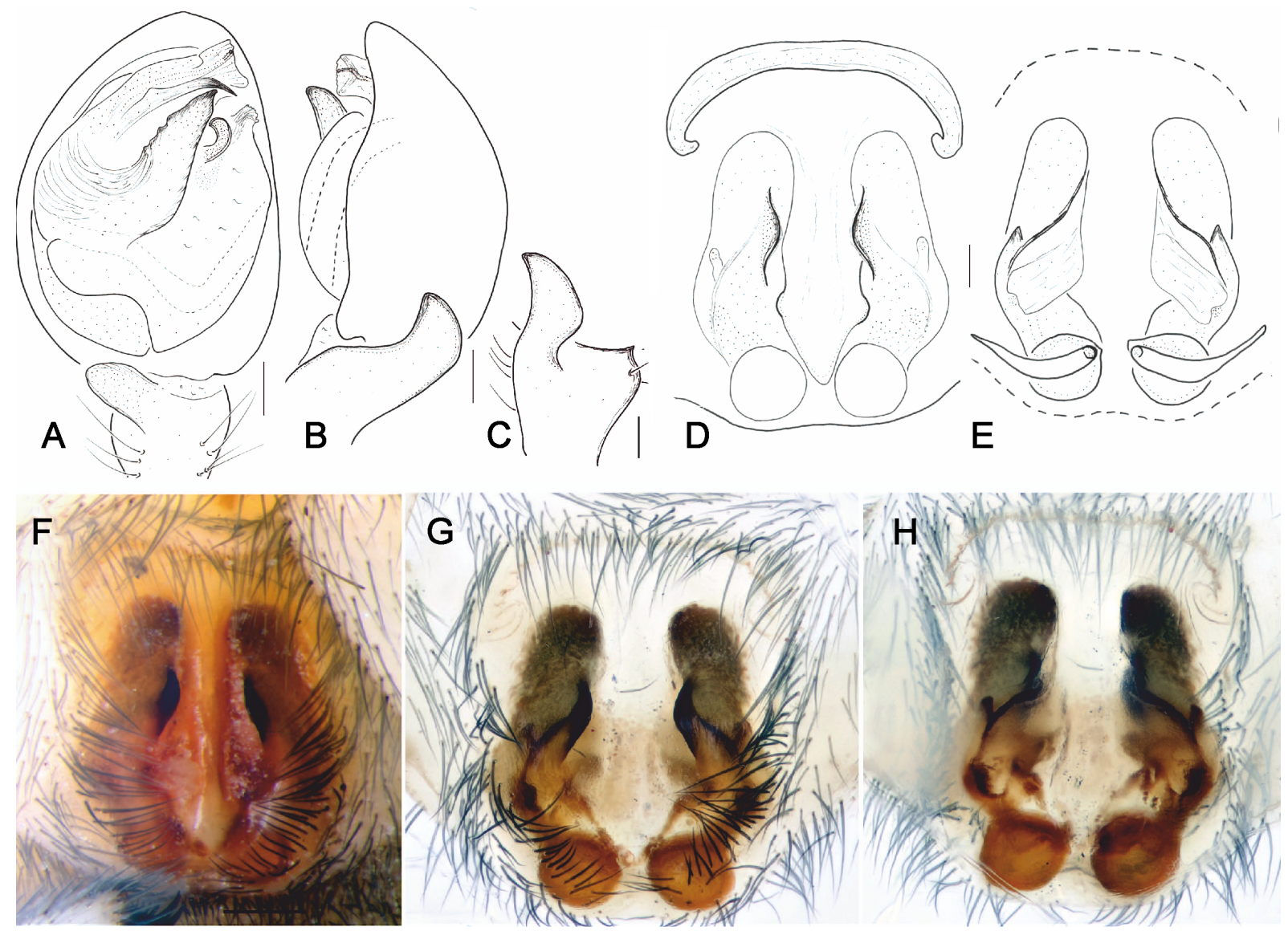

Fig. 14. Haplodrassus qashqai sp. nov. $\left(\mathrm{A}-\mathrm{C}=\right.$ holotype, ${ }^{\lambda}$, $\mathrm{MHNG}$; $\mathrm{D}-\mathrm{H}=$ paratype, $\subsetneq$ from Lorestan Province, MHNG). A-B. Palp, ventral and retrolateral views. C. Tibial apophysis, retrodorsal view. D-E. Epigyne, ventral and dorsal views. F. Intact epigyne, ventral view. G-H. Macerated epigyne, ventral and dorsal views. Scale bars: $0.1 \mathrm{~mm}$. 
Genus Marinarozelotes Ponomarev, 2020

Marinarozelotes achaemenes sp. nov.

urn:lsid:zoobank.org:act:D8C20D6A-0AB6-44F7-9CE1-2DFC53496DCA

Fig. 15

\section{Diagnosis}

The new species is mostly similar to M. cumensis (Ponomarev, 1979), M. manytchensis (Ponomarev \& Tsvetkov, 2006), M. malkini (Platnick \& Murphy, 1984) and M. mutabilis (Simon, 1878) in that the M-shaped median ridge is at the middle to upper part of the median plate, while extending further to posterior end in the congeners. It differs from M. cumensis by its long copulatory ducts extending beyond the anterior margin (vs very short and well below the anterior margin) and from the others by the shape of atrium being wider than long (vs longer than wide).

\section{Etymology}

The specific epithet is a noun in apposition, referring to the apical ancestor of the Achaemenid dynasty.

\section{Type material}

\section{Holotype}

IRAN • + ; Kohgiluyeh \& Boyer-Ahmad Province, Yasuj; 30²8’ N, 51³0’ E; 25 Jul. 1974; A. Senglet leg.; MHNG.
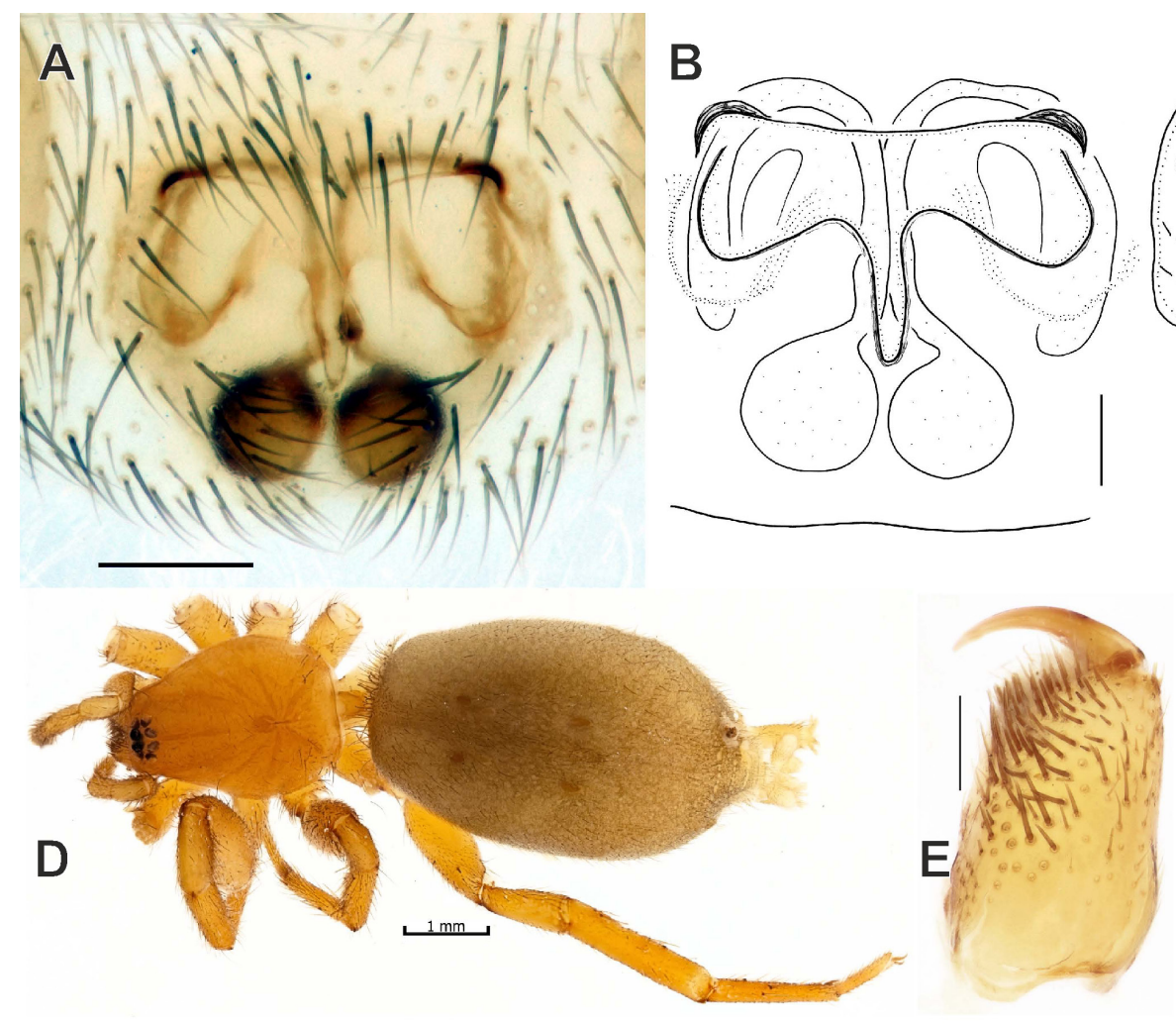
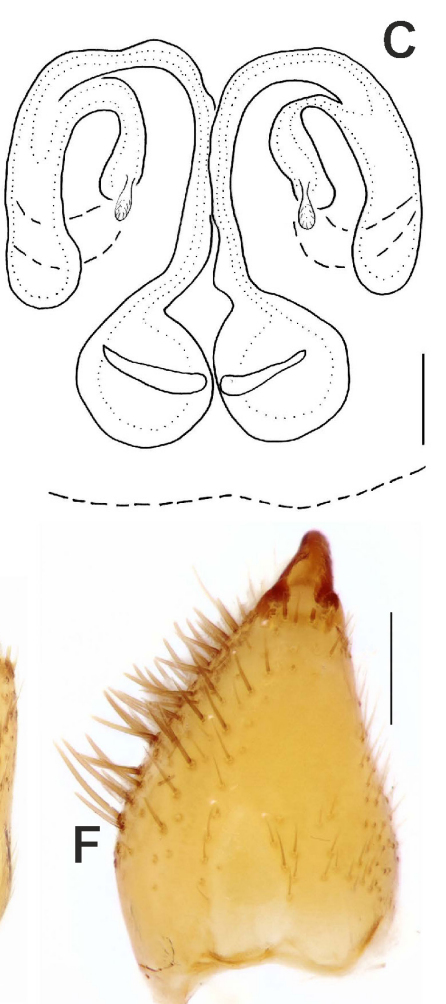

Fig. 15. Marinarozelotes achaemenes sp. nov., holotype, $q$ (MHNG). A-C. Epigyne, ventral and dorsal views. D. Habitus, dorsal view. E-F. Chelicera, posterior and anterior views. Scale bars: A, E-F $=0.2 \mathrm{~mm}$; $\mathrm{B}-\mathrm{C}=0.1 \mathrm{~mm} ; \mathrm{D}=1 \mathrm{~mm}$. 


\section{Description}

\section{Female}

Habitus as in Fig. 15D. Total length 7.28. Carapace 2.42 long, 1.84 wide. Eye sizes and interdistance of PMEs: $\mathrm{AME}=0.11, \mathrm{ALE}=0.13, \mathrm{PME}=0.15, \mathrm{PLE}=0.14, \mathrm{PME}-\mathrm{PME}=0.05$. Carapace, chelicerae, maxillae, labium and sternum light yellowish brown. Chelicera (Fig. 15E-F) without teeth, with a series of long, stiff anteromedian setae. Legs light yellowish and without annulations and with sparse spines. Abdomen grayish brown, with four dark gray cardiac sigilla dorsally. Spinnerets light yellowish and uniform in color. Measurements of legs: I: missing, II: 6.27 (1.76, 1.08, 1.32, 1.19, 0.92), III: 5.20 (1.41, 0.90, 0.98, 1.09, 0.82), IV: $7.98(2.11,1.20,1.78,1.89,1.00)$.

Epigyne as in Fig. 15A-C. Anterior margin continuous and wide; M-shaped median ridge reaching the anterior edge of receptacles, with concave moderate grooves; copulatory ducts long, extending beyond anterior margin and folding anteriorly to form glandular outgrowths; receptacles round, almost touching each other.

\section{Male}

Unknown.

\section{Distribution}

Known only from the type locality in Kohgiluyeh \& Boyer-Ahmad Province, southwestern Iran.

Genus Marjanus Chatzaki, 2018

Marjanus Chatzaki, 2018: 522.

Marjanus - Seyyar et al. 2019: 201.

\section{Type species}

Zelotes platnicki Zhang, Song \& Zhu, 2001

\section{Comments}

The genus was known to be monotypic with the type species, Marjanus platnicki (Zhang, Song \& Zhu, 2001), distributed in Greece and China (WSC 2021). Diagnosis and description are given in Chatzaki (2018).

Marjanus isfahanicus sp. nov. urn:1sid:zoobank.org:act:9CB7FC88-C04C-4670-A98D-7A3ACC436976

Fig. 16

\section{Diagnosis}

The new species differs from the generotype by having interrupted anterior margins (vs uninterrupted), a strongly rebordered W-shaped atrium (vs inconspicuous) and round receptacles (vs tubular).

\section{Etymology}

The specific epithet is an adjective and refers to Isfahan Province, Iran, the type locality of the new species. 


\section{Type material}

\section{Holotype}

IRAN • P; Isfahan Province, Qamsar \& Barzok Protected Area, $55 \mathrm{~km} \mathrm{SW}$ of Qamsar, $14 \mathrm{~km}$ NE of Kamoo, near the road of Gargash observatory; $33^{\circ} 37^{\prime}$ N, 51 ${ }^{\circ} 19^{\prime}$ E; $2710 \mathrm{~m}$ a.s.1.; 19 May 2016; P. Ponel leg.; MHNG.

\section{Description}

\section{Female}

Habitus as in Fig. 16A. Total length 3.04. Carapace 1.40 long, 1.01 wide. Eye sizes and interdistance of PMEs: $\mathrm{AME}=0.05, \mathrm{ALE}=0.07, \mathrm{PME}=0.06, \mathrm{PLE}=0.06, \mathrm{PME}-\mathrm{PME}=0.05$. Carapace and chelicerae dark brown; carapace darker at the margins, with a pattern of light patches. Chelicera with 3 promarginal teeth and 1 retromarginal tooth. Sternum, maxillae and labium light brown. Legs lighter than carapace, without annulations, tarsi lighter. Abdomen dark dorsally, light brown ventrally, without any markings. Spinnerets light gray and uniform in color. Measurements of legs: I: $3.27(0.95,0.63,0.69,0.54,0.46)$, II: 3.14 (0.91, 0.52, 0.69, 0.52, 0.50), III: 2.59 (0.74, 0.37, 0.51, 0.47, 0.50), IV: 3.98 (1.08, 0.56, 0.83, $0.92,0.59)$.

Epigyne as in Fig. 16B-G. Atrium with distinct and separate anterior hoods; lateral margins distinct, converging; endogyne with membranous bursae near copulatory openings; copulatory ducts thin, forming 2 screw-like, full lateral coils in mid part, straight posteriorly, with blind glandular heads, connected
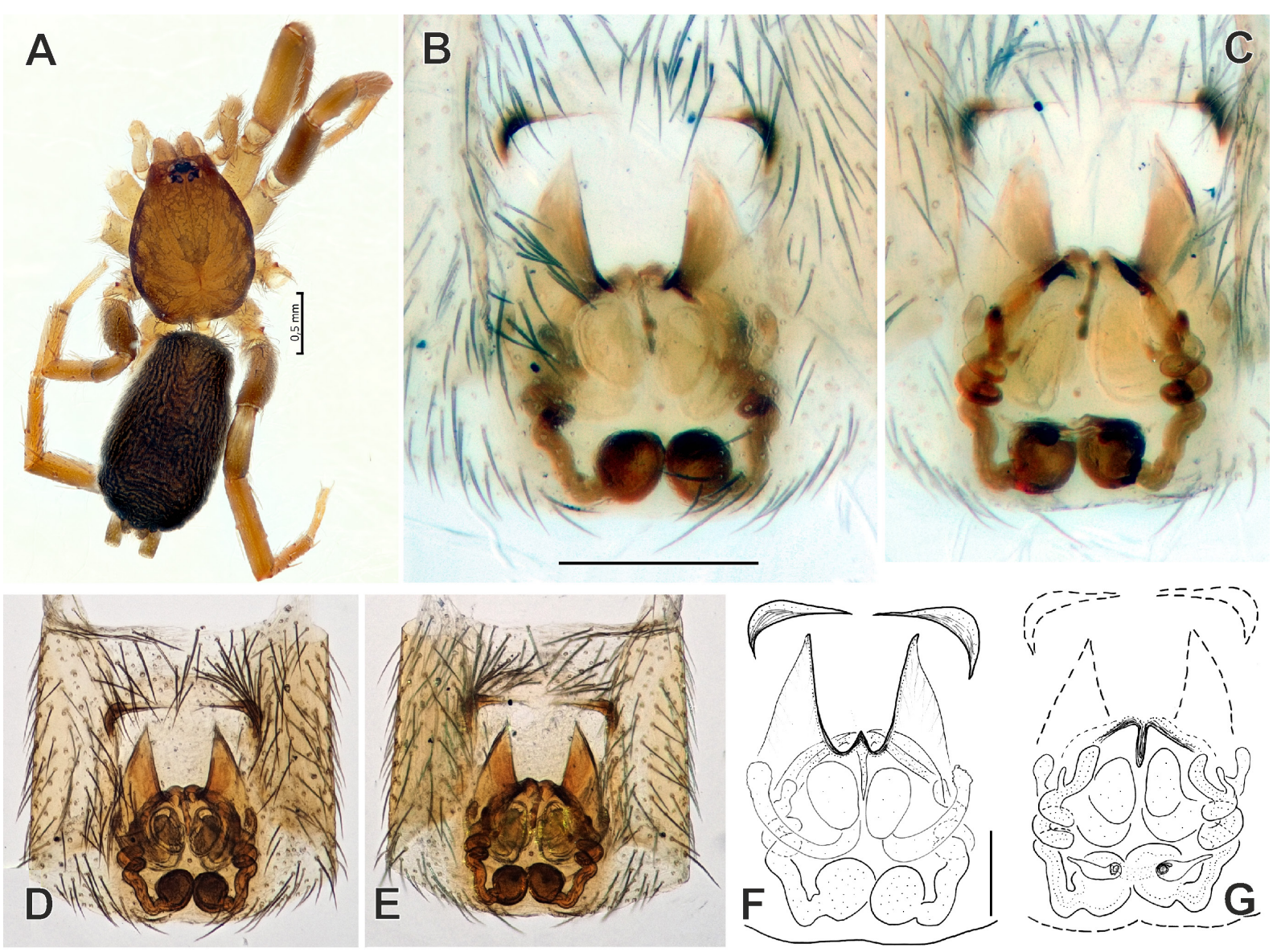

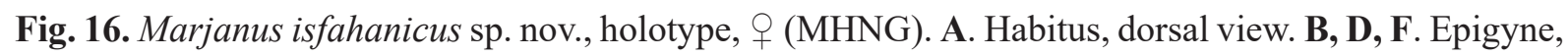
ventral view. C, E, G. Epigyne, dorsal view. Scale bars: $A=0.5 \mathrm{~mm} ; \mathrm{B}=0.2 \mathrm{~mm} ; \mathrm{F}-\mathrm{G}=0.1 \mathrm{~mm}$. 
to ventral additional bursae with extra glandular tubes; receptacles globular, 3 times as wide as ducts, touching each other, with fertilization ducts located at their upper part.

\section{Male \\ Unknown.}

\section{Comments}

Based on the similarity of the epigynal conformation to that of the type species, we tentatively place this species here in the absence of male specimens. However, only two of the three diagnostic elements of the females of this genus are met in this new species: the long, coiled copulatory ducts and additional anterior copulatory bursae and the receptacles being round rather than tubular. The latter character may have to be omitted from the generic diagnosis when more species are described and included in this genus.

\section{Distribution}

Known only from the type locality in Isfahan Province, central Iran. This is the first record of Marjanus in Iran, and the second species described in this genus.

Genus Nomisia Dalmas, 1921

Nomisia ameretatae sp. nov. urn:1sid:zoobank.org:act:91468CB5-29A9-40E4-9224-18814812AC2C

Fig. 17

\section{Diagnosis}

The new species is most similar to N. ripariensis (O. Pickard-Cambridge, 1872) and N. levyi Chatzaki, 2010 by having a similar tibial apophysis with a triangular protrusion and the tegulum extending prolaterally. It differs from them by the embolic division composed of a pike-like, straight embolus and a subtriangular terminal apophysis behind it (vs broad at base of embolus and with a claw-like terminal apophysis in $N$. ripariensis, see Chatzaki 2010: figs 47-48, and small and vertical embolus connected to a long, transverse terminal apophysis in N. levyi, see Chatzaki 2010: figs 28-29).

\section{Etymology}

The specific epithet is a noun in the genitive case and refers to Ameretat, the Avestan language name of the Zoroastrian divinity concept of immortality.

\section{Type material}

\section{Holotype}

IRAN - T; Tehran Province, Plant Pests and Diseases Research Institute park; 7-22 Jun. 2000; Y.M. Marusik leg.; MMUE.

\section{Description}

\section{Male}

Habitus as in Fig. 17A-B. Total length 7.30. Carapace 3.38 long, 2.45 wide. Sternum 1.74 long, 1.60 wide. Eye sizes and interdistance of PMEs: $\mathrm{AME}=0.12, \mathrm{ALE}=0.13, \mathrm{PME}=0.15, \mathrm{PLE}=0.13, \mathrm{PME}-\mathrm{PME}=$ 0.08. Carapace, sternum, labium, chelicerae and maxillae dark reddish brown; carapace with numerous dark lines radiating from fovea to submarginal area. Chelicera (Fig. $17 \mathrm{H})$ with serrated retromarginal keel. Legs light brown, with annulations. Abdomen light gray, dorsally with distinct darker pattern medially and marginally, ventrally with two light brown tracheal marks. Anterior spinnerets dark reddish brown, 

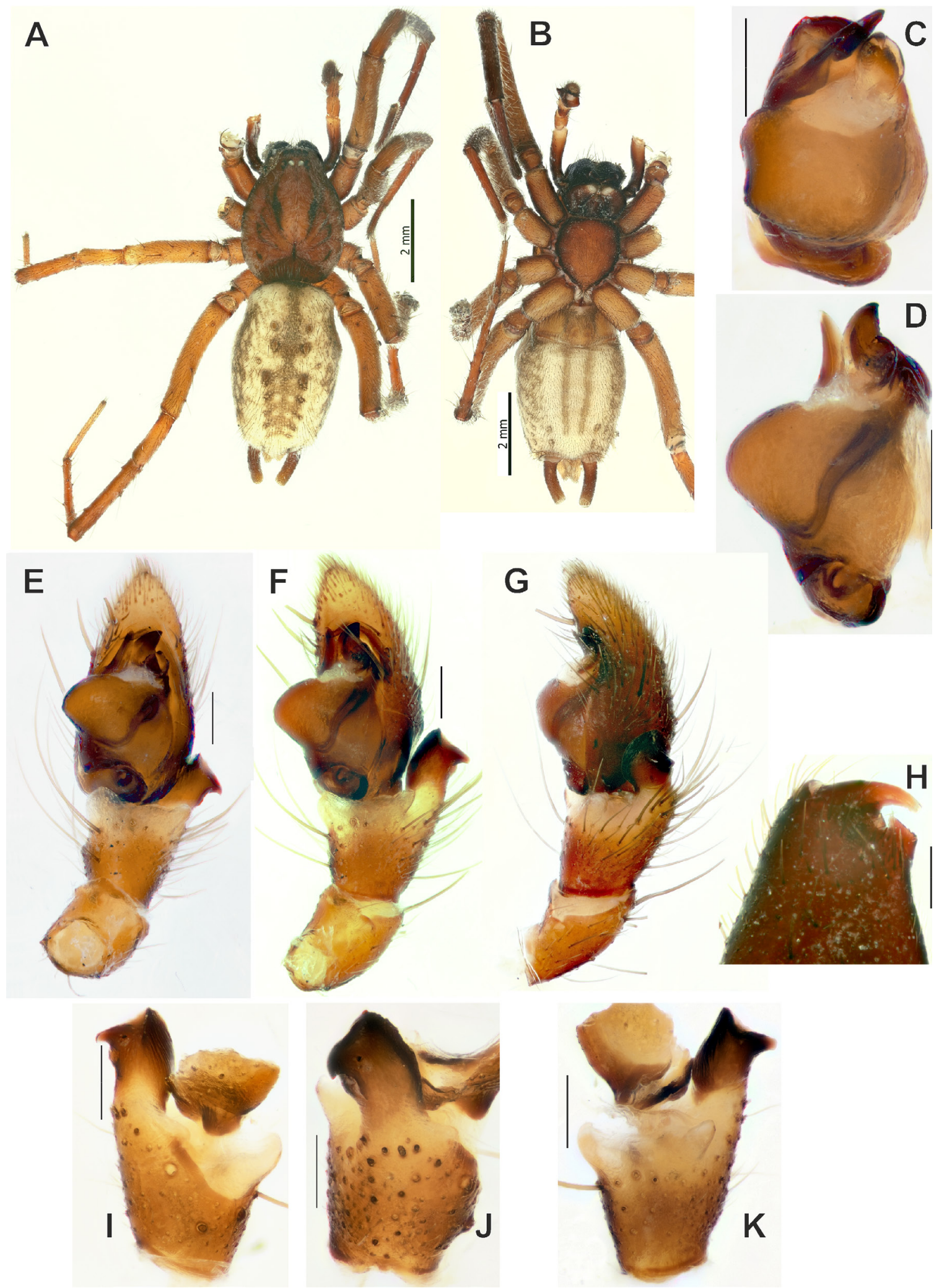

Fig. 17. Nomisia ameretatae sp. nov., holotype, $\widehat{\partial}$ (MMUE). A-B. Habitus, dorsal and ventral views. C-D. Bulb, dorsal and retrolateral views. E-G. Palp, ventral, retroventral and retrolateral views. H. Chelicera, posterior view. I-K. Tibial apophysis, dorsal, retrolateral and ventral views. Scale bars: $0.2 \mathrm{~mm}$, unless stated otherwise. 
slightly lighter in the apex. Posterior spinnerets slightly lighter than abdomen. Measurements of legs: I: 13.78 (3.48, 1.87, 3.16, 3.25, 2.02), II: missing, III: 8.32 (2.22, 1.17, 1.45, 2.10, 1.42), IV: 11.74 (3.15, $1.44,2.50,3.24,1.41)$.

Palp as in Fig. 17C-G, I-K. Tibia with small, membranous retroventral apophysis and well sclerotized retrolateral one; retrolateral apophysis shorter than tibia, broader in central part than at the base, tip rounded, central part with conical process; cymbium 2.3 times as long as wide; tegulum with massive protrusion directed prolaterally; terminal apophysis subtriangular, well sclerotized, parallel to embolus, arising behind tegulum; embolus pike-like, oblique, directed at an almost 2 o'clock position.

\section{Female}

Unknown.

\section{Distribution}

Known only from the type locality in Tehran Province, northern Iran.

Genus Prodidomus Hentz, 1847

Prodidomus inexpectatus sp. nov.

urn:1sid:zoobank.org:act:49D2D1DB-4FB3-4631-8A0C-7B8351270929

Fig. 18

\section{Diagnosis}

The new species is very similar to P. redikorzevi Spassky, 1940 from which it differs by the shape of the tibial apophysis (with longer claw-like tip, and smaller dorsal lobe).

\section{Etymology}

The specific epithet is an adjective and refers to the unexpected discovery of a new species of this genus in Iran.

\section{Type material}

\section{Holotype}

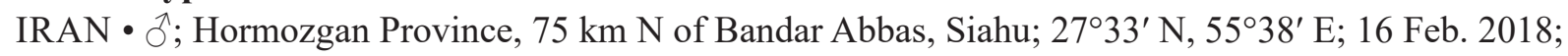
A. Zamani leg.; MHNG.

\section{Description}

\section{Male}

Habitus as in Fig. 18A-B. Total length 2.32. Carapace 0.98 long, 0.84 wide. Sternum 0.72 long, 0.55 wide. Eye sizes: $\mathrm{AME}=0.09, \mathrm{ALE}=0.08, \mathrm{PME}=0.11, \mathrm{PLE}=0.10$. Body flattened, carapace ovoid. Ocular area triangular. Carapace, sternum, labium, chelicerae and maxillae dark yellow, without any pattern and with slightly darker margins. Chelicera (Fig. 18G) without teeth. Legs the same color as carapace, without annulations. Abdomen and spinnerets light gray and without any pattern. Leg III measurements: $2.39(0.65,0.37,0.44,0.49,0.44)$, rest of the legs missing.

Palp as in Fig. 18C-F, H-I. Femur length/width ratio 3.33; tibia with broad retrolateral apophysis and small, spine-like dorsal apophysis; lateral apophysis with claw-like tip and dorsal small lobe; cymbium elongated, oval, 1.7 times as long as wide, tip rounded; tegulum protruding ventrally, in lateral view, longer than cymbium's width; embolus long, making roughly 2.25 loops. 
Female

Unknown.

\section{Distribution}

Known only from the type locality in Hormozgan Province, southern Iran.
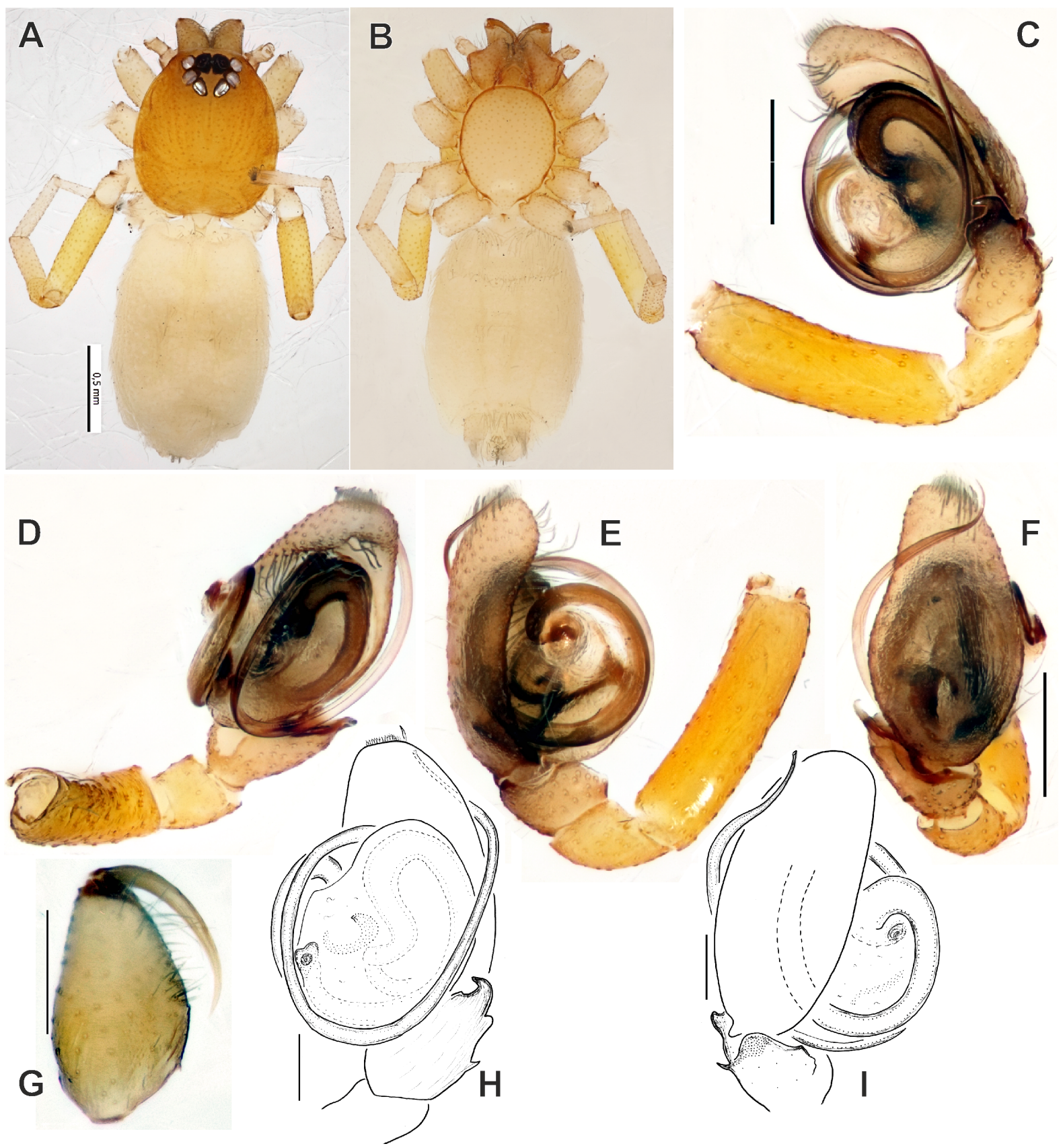

Fig. 18. Prodidomus inexpectatus sp. nov., holotype, $\widehat{\partial}$ (MHNG). A-B. Habitus, dorsal and ventral views. C-F, H-I. Palp, retrolateral, ventral, prolateral, dorsal, retroventral and prodorsal views. G. Chelicera, posterior view. Scale bars: $\mathrm{A}=0.5 \mathrm{~mm} ; \mathrm{C}, \mathrm{F}-\mathrm{G}=0.2 \mathrm{~mm} ; \mathrm{H}-\mathrm{I}=0.1 \mathrm{~mm}$. 
Genus Scotophaeus Simon, 1893

\section{Comments}

The two new species described below are tentatively placed in Scotophaeus due to the absence of males and the general taxonomic uncertainty surrounding this genus. According to Levy (1999: 437), Scotophaeus is a "cumulative taxon for medium-sized robust gnaphosids", a problem that has not been resolved; the genus requires a full revision (Murphy 2007: 51). However, the similarity of most of the somatic characters of the new species with Scotophaeus (e.g., habitus, shape of maxillae, cheliceral dentition, eye configuration [as illustrated in Murphy 2007: fig. 374], presence of scopulae on metatarsi I and II [a diagnostic character of the genus, according to Levy 1999: 437]) as well as the form of the genital organs, with a wide epigynal depression and multi-chambered receptacles, indicate that this genus is the best candidate for generic assignment.

\section{Scotophaeus anahita sp. nov. urn:lsid:zoobank.org:act:B5C9F25A-2966-43AF-91AF-994A6B783F96}

Fig. 19A-C, G-H

\section{Diagnosis}

The two new species of Scotophaeus described here, S. anahita sp. nov. and S. elburzensis sp. nov., are very similar in the structure of their epigynal sclerotization and somatic characters but are clearly different in the structure of the endogyne. In S. anahita sp. nov., the lateral ducts are spiraled (vs relatively straight, slightly curved outward in S. elburzensis sp. nov.) and the terminal lobes are smaller than the basal lobes and located anteriorly (vs larger than the basal lobes and located posteriorly in S. elburzensis sp. nov.) (cf. Fig. 19B, E). Similarly, they resemble S. nanus Wunderlich, 1995 in the form of the epigynal atrium, but the configuration of the spermathecal cluster is very different from both of the new species (see Wunderlich 1995: figs 6-8).

\section{Etymology}

The specific epithet is a noun in apposition and refers to the divinity of the Waters (associated with fertility, healing and wisdom) in Persian mythology.

\section{Type material}

\section{Holotype}

IRAN • + ; Isfahan Province, Qamsar \& Barzok Protected Area, $55 \mathrm{~km} \mathrm{SW}$ of Qamsar, $14 \mathrm{~km} \mathrm{NE}$ of Kamoo, near the road of Gargash observatory; $33^{\circ} 37^{\prime}$ N, 51 $1^{\circ} 19^{\prime}$ E; 2710 m a.s.1.; 19 May 2016; P. Ponel leg.; ZMMU.

\section{Description}

Female

Total length 11.7. Carapace 5.90 long, 3.80 wide. Eye sizes and interdistance of PMEs: $\mathrm{AME}=0.18$, $\mathrm{ALE}=0.18, \mathrm{PME}=0.20, \mathrm{PLE}=0.20, \mathrm{PME}-\mathrm{PME} 0.15$. Carapace yellowish brown, covered with dark, short setae. Chelicera (Fig. 19G) dark brown (almost black), with 3 promarginal teeth. Sternum yellowish brown with dark border, covered with black setae. Maxillae and labium dark brown with white tip. Maxillae longer than wide, with medial indentation on the external edge. Legs yellowish brown with lighter femora and darker brownish metatarsi and tarsi. Abdomen gray, covered with white plumose hairs and dark setae dorsally, and yellow with dark setae ventrally. Spinnerets yellowish brown and uniform in color. Measurements of legs: I: 14.90 (4.18, 2.43, 3.48, 2.83, 2.00), II: 13.95 (3.93, 2.28, 3.18, 2.75, 1.83), III: 13.45 (3.75, 1.90, 2.95, 3.00, 1.85), IV: 18.23 (4.85, 2.20, 4.08, 5.05, 2.05). Spination: I: Fe: 
2d, 1pl; Ti: 4v; Mt: 2v. II: Fe: 2d, 2pl; Ti: 4v; Mt: 2v. III: Fe: 2d, 4pl, 2rl; Ti: 1d, 3pl, 3rl, 6v; Mt: 5pl, 6rl, 9v. IV: Fe: 3d, 2pl, 2rl; Ti: 2d, 3pl, 3rl, 6v; Mt: 6pl, 6rl, 6v.

Epigyne as in Fig. 19A-C, H. Epigynal plate almost as long as wide, with transverse atrium posteriorly; atrium with chitinized 'ridge' of the lateral ducts $(r L D)$ posteriorly and bordered by lateral margin $(\mathrm{Lm})$; lateral ducts $(L d)$ wide and spiraled; each receptacle with two pairs of concentric sacs ( $B l$ and $T l)$; dorsal blind tubes arise from the second pair.

\section{Male}

Unknown.

\section{Distribution}

Known only from the type locality in Isfahan Province, central Iran.
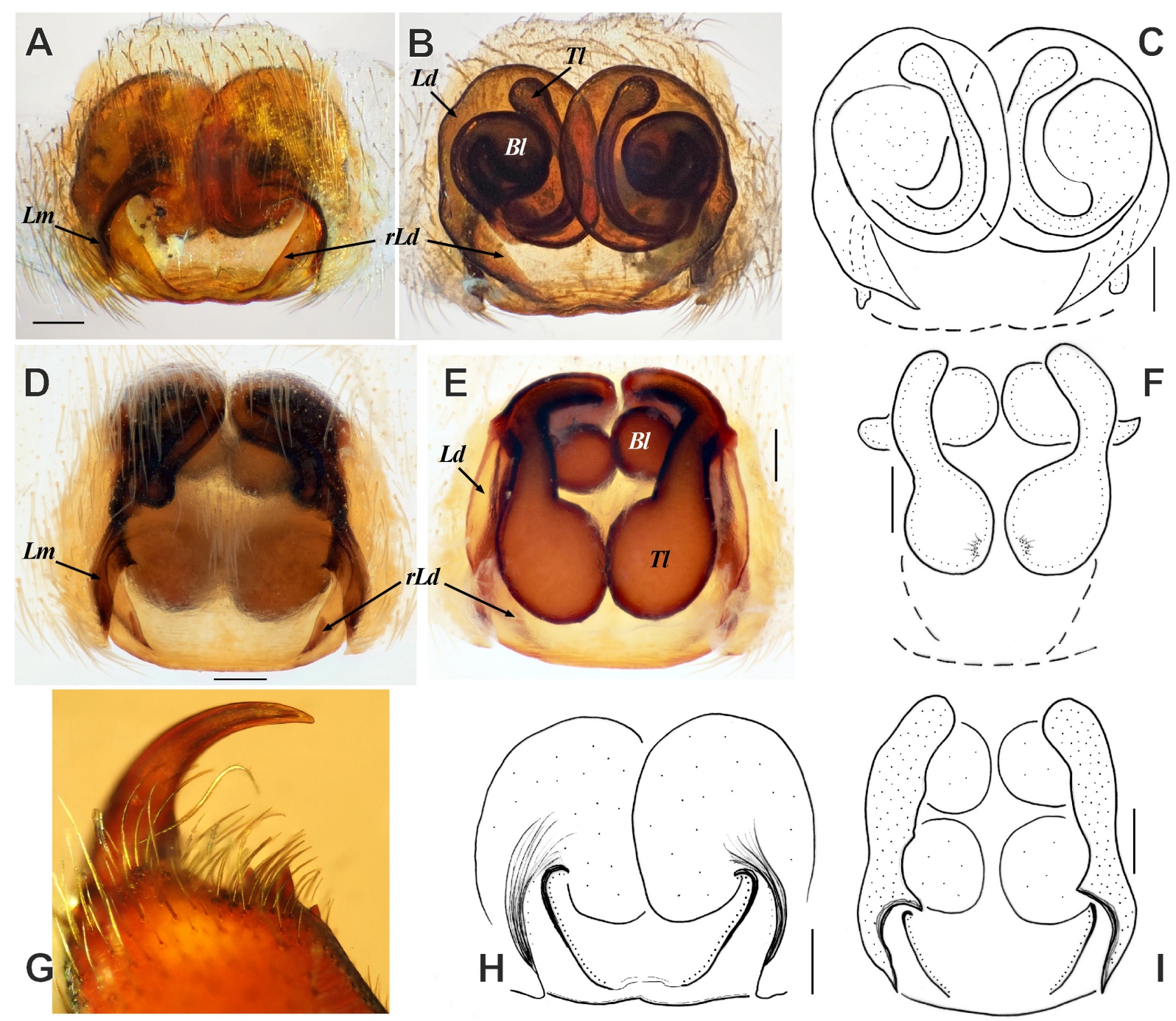

Fig. 19. A-C, G-H. Scotophaeus anahita sp. nov., holotype, $q$ (ZMMU). A, H. Epigyne, ventral view. B-C. Epigyne, dorsal view. G. Chelicera, posterior view. - D-F, I. Scotophaeus elburzensis sp. nov., ㅇ (D-E = specimen from Tehran Province, SMF; F, I = holotype, ZMMU). D, I. Epigyne, ventral view. E-F. Epigyne, dorsal view. Abbreviations: $B l=$ basal lobe; $L d=$ lateral duct; $L m=$ lateral margin; $r L d=$ ridge of lateral duct; $T l=$ terminal lobe. Scale bars: $A, C, F, H-I=0.1 \mathrm{~mm}$; D-E $=0.2 \mathrm{~mm}$. 
Scotophaeus elburzensis sp. nov. urn:1sid:zoobank.org:act:CD564644-82B1-4E91-974E-9C6BEEB5CBA3

Figs 19D-F, I, 20

\section{Diagnosis}

The new species is easily distinguished from its congeners by the atrium which is trapezoidal posteriorly and anteriorly an open dome, and by the peculiar placement of the two pairs of receptacles, one vertical to the other. As in the similar $S$. anahita sp. nov., the posterior part of the epigynal atrium is most similar to that of S. nanus (see Wunderlich 1995: figs 6-8), but the rest of the epigynal characters are unique enough to consider it a new species. This species can be further diagnosed from the related S. anahita sp. nov. by the lateral ducts being relatively straight and slightly curved outward (vs spiraled) and the terminal lobes being larger than the basal lobes and located posteriorly (vs smaller than basal lobes and located anteriorly).

\section{Etymology}

The specific epithet is an adjective and refers to the Elburz Mountain Range, from where the specimens have been collected.

\section{Type material}

\section{Holotype}

IRAN • ' ; Zanjan Province, Gheydar; 3606' N, 48³4' E; 25 May 2017; L. Karami leg.; ZMMU.

\section{Other material examined}

IRAN • 1 क; Tehran Province, Koolak (= Kolakchal); 2400-2500 m a.s.1.; 25 May 1978; J. Martens and H. Pieper leg.; SMF.
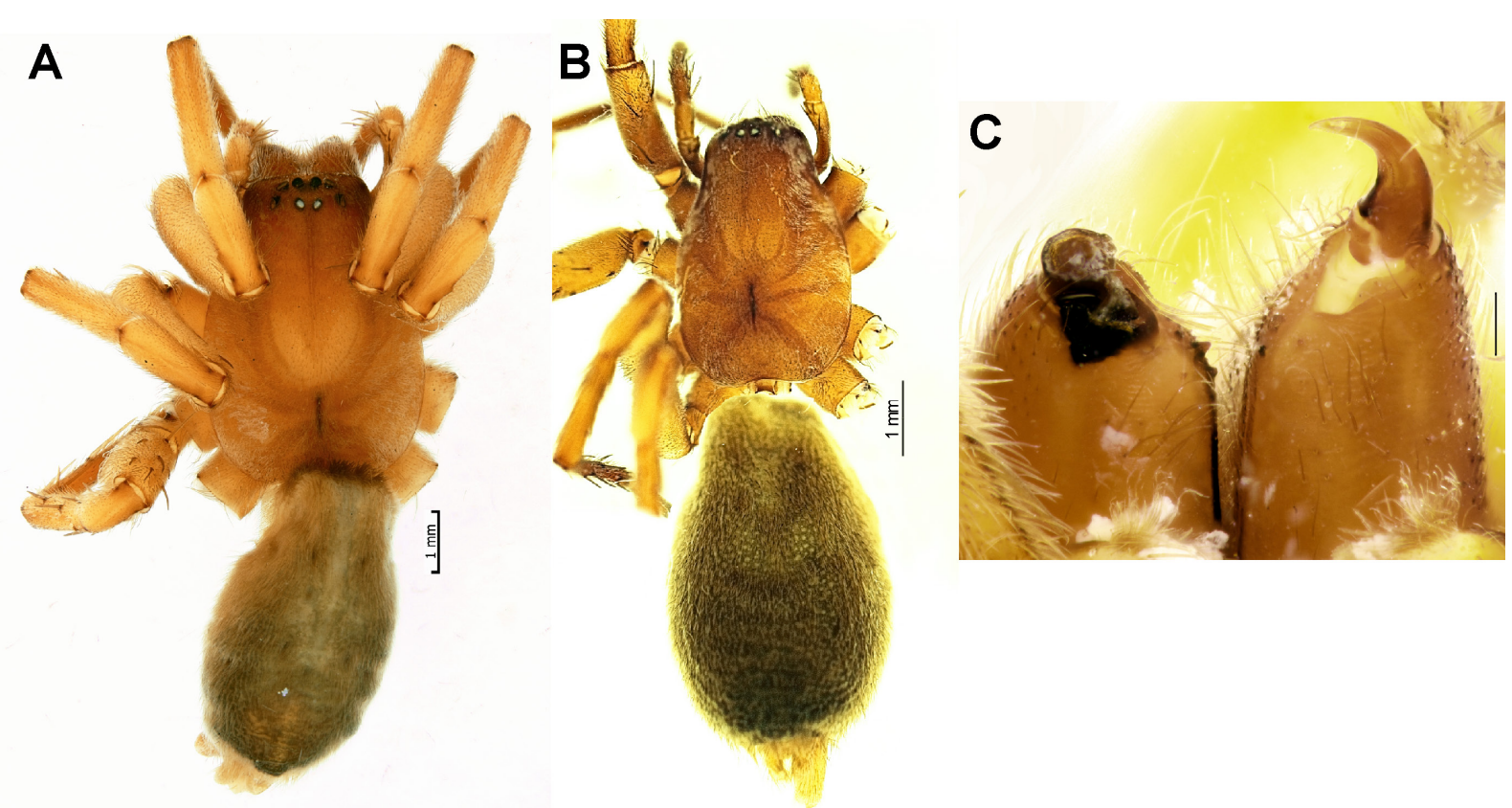

Fig. 20. Scotophaeus elburzensis sp. nov. (A, $\mathrm{C}=q$ from Tehran Province, $\mathrm{SMF} ; \mathrm{B}=$ holotype,, , $\mathrm{ZMMU}$ ). A-B. Habitus, dorsal view. C. Chelicerae, posterior view. Scale bars: $0.2 \mathrm{~mm}$, unless stated otherwise. 


\section{Description}

Female (holotype)

Habitus as in Fig. 20A-B. Total length 10.8. Carapace 5.25 long, 3.45 wide. Eye sizes and interdistance of PMEs: $\mathrm{AME}=0.17, \mathrm{ALE}=0.15, \mathrm{PME}=0.14, \mathrm{PLE}=0.17, \mathrm{PME}-\mathrm{PME}=0.13$. Carapace yellowish brown, covered with dark, short setae. Chelicerae (Fig. 20C) brown, with 3 promarginal teeth. Sternum yellowish brown with dark borders, covered with black setae. Maxillae and labium yellow-brown with white tips. Legs yellowish brown with lighter femora. Abdomen gray, covered with white plumose hairs and dark setae dorsally, and grayish white with dark setae ventrally. Spinnerets yellowish brown and uniform in color. Measurements of legs: I: 12.20 (3.50, 1.95, 2.85, 2.30, 1.60), II: 12.00 (3.50, 1.95, 2.70, 2.30, 1.55), III: 11.50 (3.30, 1.70, 2.40, 2.55, 1.55), IV: 15.25 (4.00, 2.00, 3.45, 4.05, 1.75). Spination: I: Fe: 2d, 1pl; Ti: 4v; Mt: 2v. II: Fe: 2d, 2pl; Ti: 3v; Mt: 2v. III: Fe: 3d, 2pl, 2rl; Ti: 1d, 3pl, 3rl, 6v; Mt: 5pl, 5rl, 6v. IV: Fe: 3d, 2pl, 2rl; Ti: 2d, 3pl, 3rl, 6v; Mt: 5pl, 5rl, 6v.

Epigyne as in Fig. 19D-F, I. Atrium bordered by lateral margin $(L m)$; lateral ducts $(L d)$ slightly curved outward, originating posteriorly to the atrium, forming a chitinized 'ridge' to the prolateral side of the lateral margin $(r L D)$; each receptacle consists of two spherical lobes $(B l$ and $T l)$ connected by large copulatory ducts.

\section{Male}

Unknown.

\section{Comments}

There are differences in the size and position of the receptacles between the type specimen from Zanjan (Fig. 19F, I) and the additional material examined from Tehran (Fig. 19D-E), which are considered intraspecific variations.

\section{Distribution}

Known only from the listed localities in Zanjan and Tehran Provinces, northwestern and northern Iran.

Genus Sosticus Chamberlin, 1922

\section{Comments}

The genus is currently known by 10 species, including two from the Nearctic. The Palearctic species S. loricatus (L. Koch, 1866) and seven species from India, are all known from females and probably misplaced in this genus (WSC 2021).

Sosticus montanus sp. nov.

urn:1sid:zoobank.org:act:9C05213D-7ACA-4312-A314-26D6EA50A334

Fig. 21

\section{Diagnosis}

Epigyne of the new species is most similar to that of S. loricatus but differs by the shape of atrium and the copulatory ducts: atrium triangular, wider posteriorly (vs wider anteriorly) and the ducts converge medially and diverge anteriorly (vs opposite).

\section{Etymology}

The specific epithet is an adjective and refers to the mountainous habitat of the new species in the Zagros Mountain Range. 


\section{Type material}

\section{Holotype}

IRAN • +; Ilam Province, Abdanan; 3253’ N, 47³0' E; Jul. 2015; A. Zamani leg.; MHNG.

\section{Description}

\section{Female}

Habitus as in Fig. 21C. Total length 2.68. Carapace 1.67 long, 1.32 wide. Eye sizes and interdistance of PMEs: $\mathrm{AME}=0.06, \mathrm{ALE}=0.08, \mathrm{PME}=0.11, \mathrm{PLE}=0.07, \mathrm{PME}-\mathrm{PME}=0.04$. Carapace, chelicerae, sternum, maxillae and labium yellow. Chelicera (Fig. 21I) with 3 promarginal teeth. Abdomen pale, yellowish, with four dorsal sigilla, ventrally with distinct tracheal marks. Spinnerets pale and uniform in color. All legs missing.
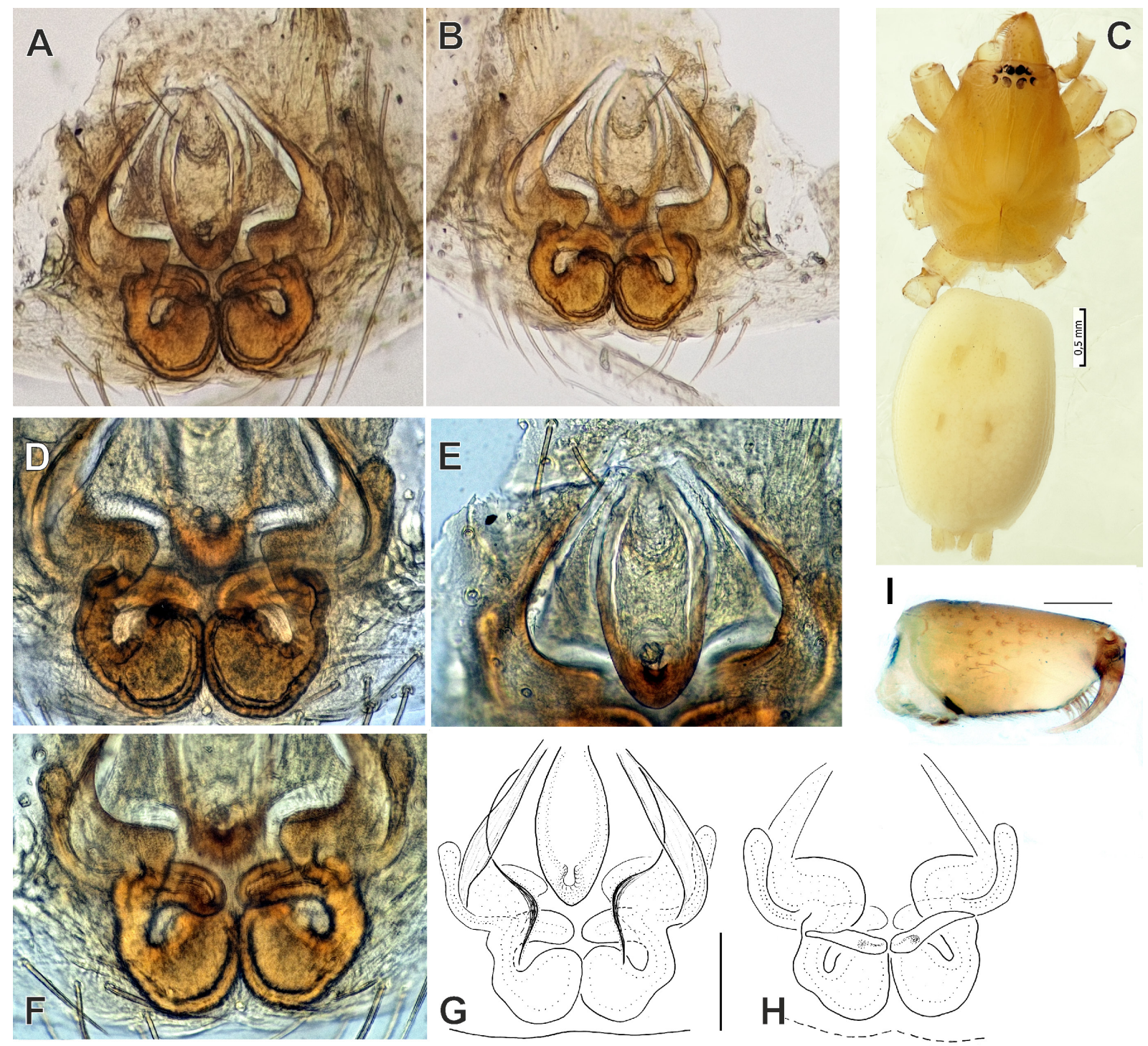

Fig. 21. Sosticus montanus sp. nov., holotype, $\uparrow$ (MHNG). A, E, G. Epigyne, ventral view. B, D, F, H. Epigyne, dorsal view. C. Habitus, dorsal view. I. Chelicera, posterior view. Scale bars: $\mathrm{C}=0.5 \mathrm{~mm}$; $\mathrm{G}-\mathrm{H}=0.1 \mathrm{~mm} ; \mathrm{I}=0.2 \mathrm{~mm}$. 
Epigyne as in Fig. 21A-B, D-H. Atrium triangular; scape large, longer than atrium; receptacles round, touching each other; copulatory ducts semicircular, converging anteriorly; receptacles and ducts form 2 vertical arcs in opposite directions; accessorial duct long, directed anteriorly and terminating at the level of mid part of the scape.

\section{Male}

Unknown.

\section{Distribution}

Known only from the type locality in Ilam Province, western Iran.

Genus Synaphosus Platnick \& Shadab, 1980

Synaphosus martinezi sp. nov. urn:1sid:zoobank.org:act:F20F9B11-21B2-4BE3-81AF-26E4A853ABFD

Figs $22-23$

\section{Diagnosis}

The male of the new species is somewhat similar to that of S. trichopus (Roewer, 1928) by having a simple conductor with only one arm but differs by lacking a palpal patellar apophysis (vs present) and a longer embolus originating at the ca 2 o'clock position (vs 5-6 o'clock). The female of $S$. martinezi sp. nov. is most similar to that of $S$. nanus (O. Pickard-Cambridge, 1872) by having an anterior hood and longitudinally oriented copulatory ducts but differs by having lateral hoods (vs lacking in S. nanus).

\section{Etymology}

The new species is named after Cuban myriapodologist Carlos Alberto Martínez-Muñoz (University of Turku, Finland), a friend of the first author.

\section{Type material}

\section{Holotype}

IRAN - I'; Kohgiluyeh \& Boyer-Ahmad Province, road to Charam; 30²8' N, 5050' E; 22 May 1974; A. Senglet leg.; MHNG.

\section{Paratypes}

IRAN • 3 우; same collection data as for holotype; MHNG.

\section{Description}

\section{Male}

Habitus as in Fig. 22A. Total length 3.13. Carapace 1.19 long, 0.89 wide. Eye sizes and interdistance of PMEs: $\mathrm{AME}=0.06, \mathrm{ALE}=0.07, \mathrm{PME}=0.06, \mathrm{PLE}=0.06, \mathrm{PME}-\mathrm{PME}=0.04$. Carapace, chelicerae, maxillae, labium and sternum light brown, without any markings. Chelicera (Fig. 22C-D) with 4 promarginal teeth and 1 retromarginal tooth. Legs light yellowish and without annulations. Abdomen light grayish brown, with mottled darker patterns posteriorly. Spinnerets yellowish and uniform in color. Measurements of legs: I: $2.32(0.69,0.39,0.53,0.37,0.34)$, Fe II: 0.69 (rest of the segments missing), III: $2.12(0.67,0.25,0.44,0.42,0.34)$, IV: $3.02(0.78,0.46,0.63,0.70,0.45)$.

Palp as in Figs 22E-G, 23A-B. Femur and patella unmodified; tibia with triangular retrolateral apophysis and small retroventral apophysis; cymbium ca 1.9 times as long as wide; tegulum almost round with 
spermophor perpendicular to its margin; conductor reverse S-shaped, lacking additional arms and with sclerotized, filiform tip; embolus long, filamentous, originating at ca 2 o'clock position.

\section{Female}

Habitus as in Fig. 22B. Total length 3.86. Carapace 1.35 long, 0.94 wide. Eye sizes and interdistance of PMEs: AME $=0.05, \mathrm{ALE}=0.07, \mathrm{PME}=0.07, \mathrm{PLE}=0.06$, PME-PME $=0.04$. Coloration as in male, slightly darker, with more uniformly colored abdomen. Chelicera with 4 promarginal teeth and 1 retromarginal tooth. Measurements of legs: I: 3.10 (0.93, 0.63, 0.67, 0.43, 0.44), II: 2.62 (0.81, 0.49, 0.51 , $0.43,0.38)$, III: $2.22(0.61,0.35,0.42,0.42,0.42), \mathrm{Fe}$ and Pa IV: $0.90,0.54$ (rest of the segments missing).

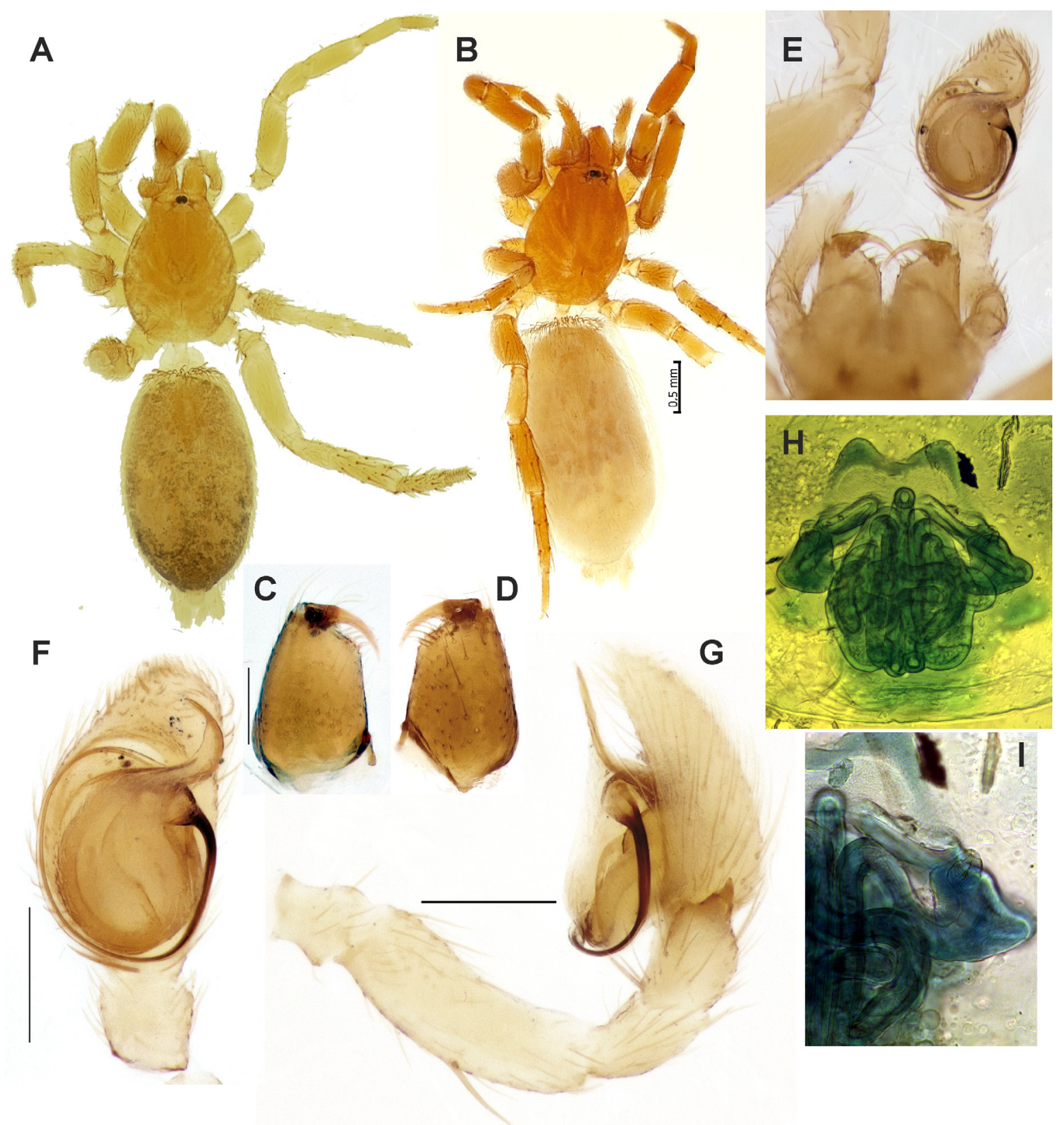

Fig. 22. Synaphosus martinezi sp. nov. (A, $\mathrm{C}-\mathrm{G}=$ holotype, ${ }^{\AA}$, MHNG; $\mathrm{B}, \mathrm{H}-\mathrm{I}=$ paratype,, , MHNG). A-B. Habitus, dorsal view. C-D. Chelicera, posterior and anterior views. E-G. Palp, ventral and retrolateral views. H-I. Epigyne, dorsal view. Scale bars: $0.2 \mathrm{~mm}$, unless stated otherwise. 
Epigyne as in Figs 22H-I, 23C-G. Anterior hood distinct, with a pair of small lateral hoods (= copulatory openings); copulatory ducts as 4 longitudinal loops.

\section{Distribution}

Known only from the type locality in Kohgiluyeh \& Boyer-Ahmad Province, southwestern Iran.

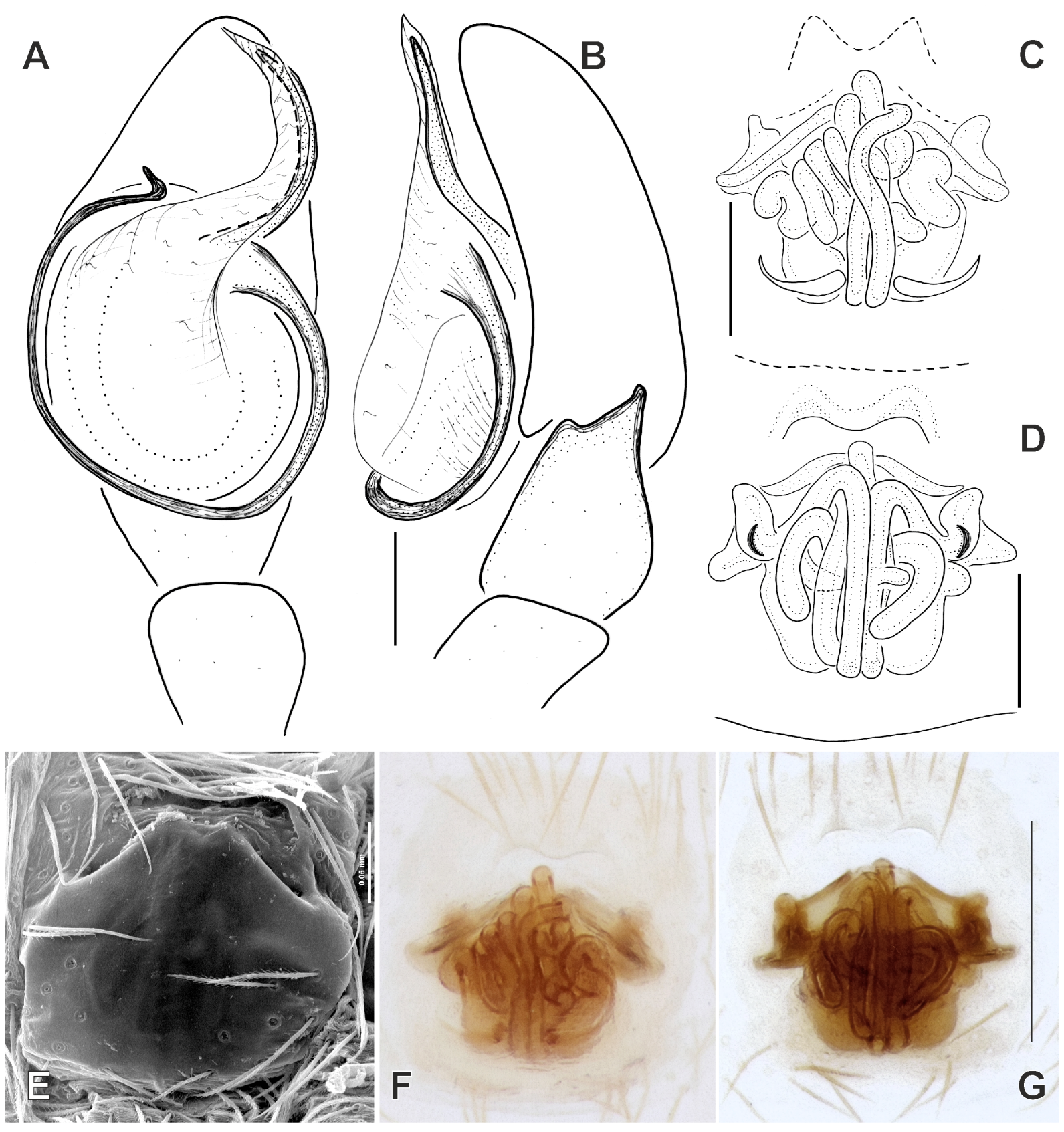

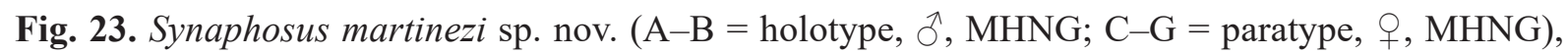
copulatory organs. A-B. Palp, ventral and retrolateral views. C, E-F. Epigyne, ventral view. D, G. Epigyne, dorsal view. Scale bars: A-D $=0.1 \mathrm{~mm} ; \mathrm{E}=0.05 \mathrm{~mm} ; \mathrm{G}=0.2 \mathrm{~mm}$. 
Genus Zagrotes gen. nov.

urn:lsid:zoobank.org:act:CB64BAF3-DC7E-4A1D-87FE-CE94F4B47651

\section{Type species}

Zagrotes apophysalis sp. nov., from southwestern Iran.

\section{Diagnosis}

The male of the new genus differs from other Zelotinae Platnick, 1990 occurring in the region by the large modified palpal patella being longer than the tibia, with a swollen proximal part, swollen base of the tibial apophysis, the tibia being two times wider distally than proximally and the bifid tibial apophysis. The female of Zagrotes gen. nov. differs from other species of Zelotinae (except for some female Berinda spp.) by having a distinct flexible scape with a digitiform tip.

\section{Etymology}

A combination of 'Zagros', a mountain range in Iran, Iraq and southeastern Turkey, and 'Zelotes', referring to the distribution and affinity of the new genus, respectively.

\section{Description}

Same as for the type species.

\section{Comments}

Although the epigyne is different from those of all other genera of Zelotinae, and the male palp has modifications unknown in other members of this subfamily, the genus is placed in Zelotinae due to the presence of a preening comb on metatarsus III.

\section{Composition}

Only the type species.

\section{Distribution}

Southwestern and southern Iran.

$$
\begin{aligned}
& \text { Zagrotes apophysalis sp. nov. } \\
& \text { urn:1sid:zoobank.org:act:E8CB0012-A945-45E7-9231-97E024B16661 }
\end{aligned}
$$

Figs 24-26

\section{Diagnosis}

Same as for the genus.

\section{Etymology}

The specific epithet is an adjective and refers to the greatly enlarged retrolateral tibial apophysis of the male palp.

\section{Type material}

\section{Holotype}

IRAN • ${ }^{\lambda}$; Kohgiluyeh \& Boyer-Ahmad Province, Seyyed Safi; May 2017; A. Hosseinpour leg.; MHNG.

\section{Paratypes}

IRAN • 1 \%; same collection data as for holotype; MHNG $\bullet 1$; Hormozgan Province, $75 \mathrm{~km} \mathrm{~N}$ of Bandar Abbas, Siahu; 27³3' N, 55³8' E; 16 Feb. 2018; A. Zamani leg.; MHNG. 


\section{Description}

\section{Male}

Habitus as in Fig. 24A. Total length 4.29. Carapace 1.96 long, 1.38 wide. Eye sizes and interdistance of PMEs: $\mathrm{AME}=0.09, \mathrm{ALE}=0.08, \mathrm{PME}=0.09, \mathrm{PLE}=0.07, \mathrm{PME}-\mathrm{PME}=0.06$. Carapace, chelicerae, maxillae, labium and sternum light brown. Legs the same color as carapace and without annulations. Chelicerae (Fig. 24E) with 5 pro- and 2 retromarginal teeth. Abdomen light grayish brown, without any pattern; scutum short, triangular, almost two times as wide as long. Spinnerets light grayish and uniform in color. Measurements of legs: I: 5.60 (1.48, 1.03, 1.23, 1.09, 0.77), II: 4.51 (1.16, 0.87, 0.95, 0.93, 0.60), III: 3.79 (1.06, 0.54, 0.74, 0.88, 0.57), IV: $6.00(1.53,0.90,1.28,1.52,0.77)$.

Palp as in Figs 24C-D, 25. Femur 3 times as long as wide, slightly longer than patella + tibia, or cymbium; patella modified, longer than tibia, with swollen proximal part; tibia modified, swollen retrolaterally, 2 times wider in the middle than in base, apophysis long, about 4 times as long as wide, deeply bifid, with ventral arm rounded on the tip and dorsal arm spine-like, sharply pointed; cymbium elongated, 2.3 times as long as wide, with cone-shaped tip; tegulum twice as long as wide, with large median
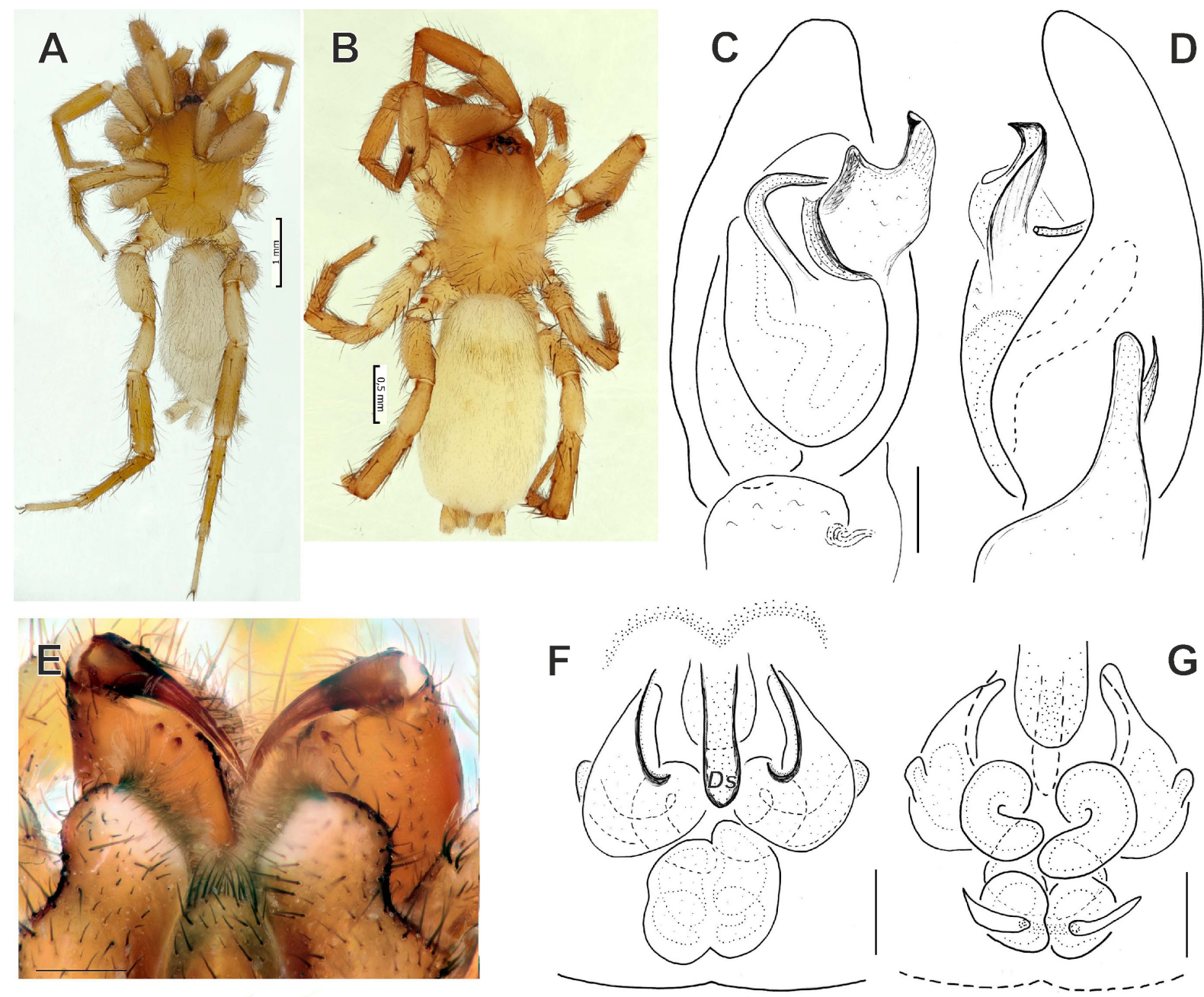

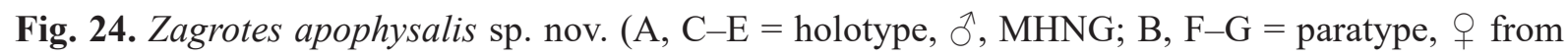
Kohgiluyeh \& Boyer-Ahmad Province, MHNG). A-B. Habitus, dorsal view. C-D. Palp, ventral and retrolateral views. E. Chelicerae, posterior view. F-G. Epigyne, ventral and dorsal views. Abbreviation: $D s=$ digitiform scape. Scale bars: $\mathrm{A}=1 \mathrm{~mm} ; \mathrm{B}=0.5 \mathrm{~mm} ; \mathrm{C}-\mathrm{D}, \mathrm{F}-\mathrm{G}=0.1 \mathrm{~mm}$; $\mathrm{E}=0.2 \mathrm{~mm}$. 
apophysis, as long as bulb's width, apophysis with 2 arms; spermophor U-shaped in ventral view; tegulum with membranous, finger-shaped apophysis near the base of embolus (not easily discernible); embolus filamentous, originating at the middle of the tegulum and encircling it, reaching the retrolateral margin of the cymbium.
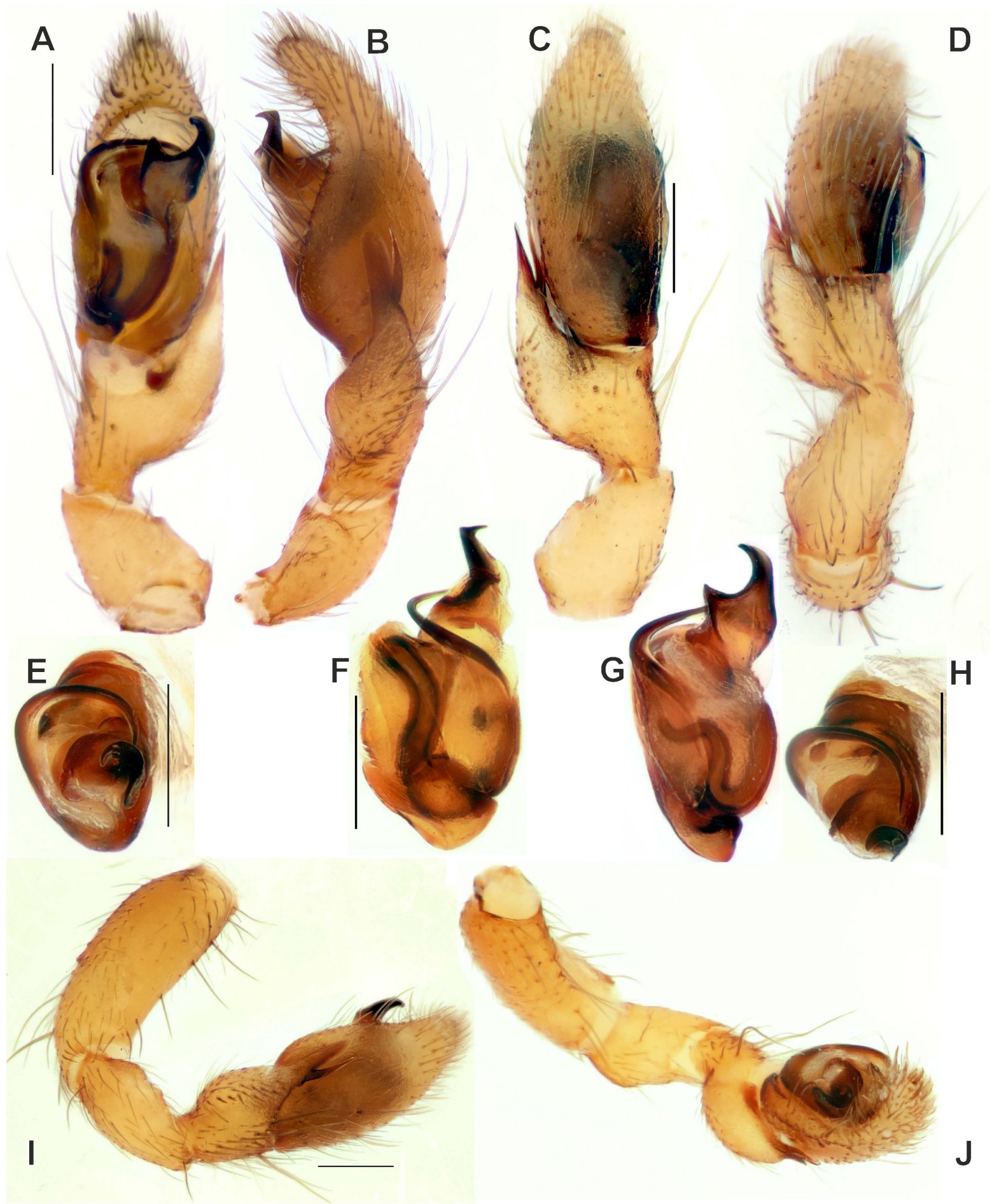

Fig. 25. Zagrotes apophysalis sp. nov., holotype, §̊ (MHNG), palp. A-D. Palp, ventral, retrolateral, dorsal and retrodorsal views. E, H. Bulb, apical view. F-G. Bulb, prolateral and proventral views. I-J. Full palp, dorsolateral and ventral views. Scale bars: $0.2 \mathrm{~mm}$. 
Female (paratype, Kohgiluyeh \& Boyer-Ahmad Province)

Habitus as in Fig. 24B. Total length 5.55. Carapace 2.14 long, 1.46 wide. Eye sizes and interdistance of PMEs: $\mathrm{AME}=0.07, \mathrm{ALE}=0.09, \mathrm{PME}=0.09, \mathrm{PLE}=0.06, \mathrm{PME}-\mathrm{PME}=0.06$. Coloration and somatic features as in male. Measurements of legs: I: $5.87(1.51,1.10,1.33,1.08,0.85)$, II: 4.61 (1.22, 0.76, 1.00, 0.93, 0.70), III: 4.24 (1.15, 0.64, 0.85, 0.94, 0.66), IV: $6.07(1.58,0.89,1.28,1.53,0.79)$.

Epigyne as in Figs 24F-G, 26. Epigynal plate longer than wide; with distinct scape (Ds), basal part conical, goffered, tip heavily sclerotized, digitiform; posterior part of atrium with distinct margins and copulatory openings; copulatory ducts long, coiled and ending posteriorly in broad sacs.

\section{Distribution}

Known from the listed localities in Kohgiluyeh \& Boyer-Ahmad and Hormozgan Provinces, southwestern and southern Iran.

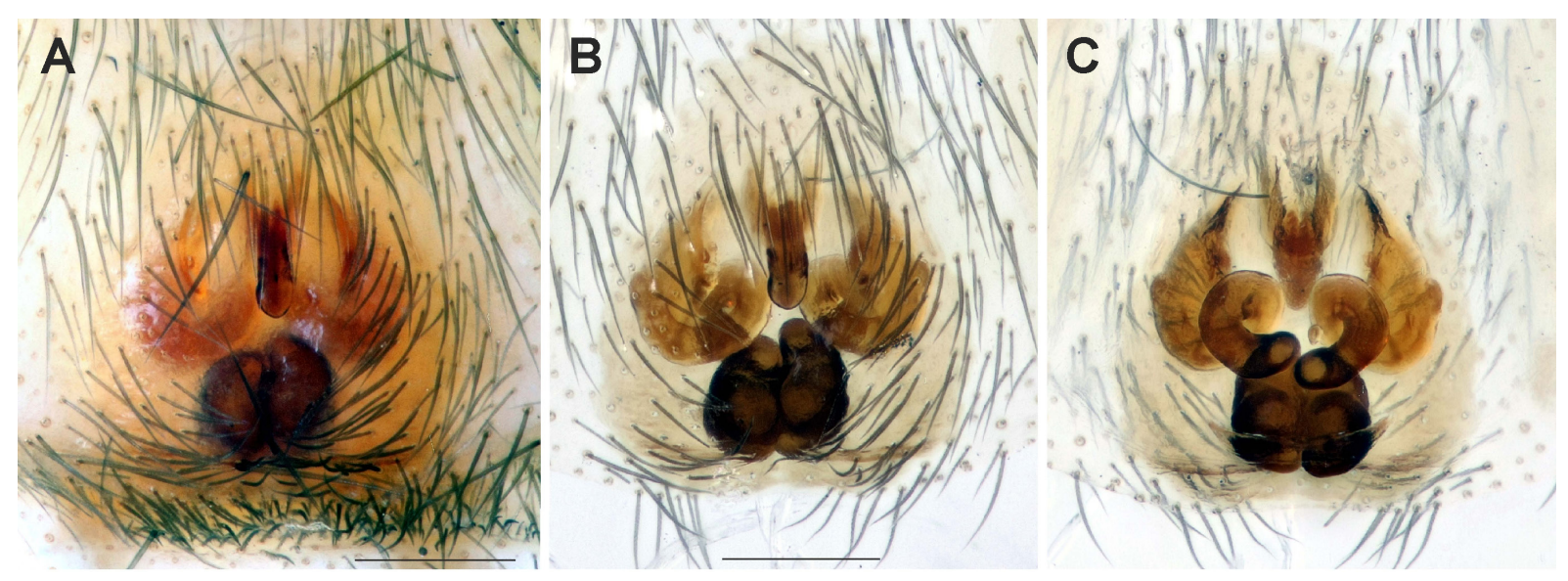

Fig. 26. Zagrotes apophysalis sp. nov., paratype, $\uparrow$ from type locality (MHNG), epigyne. A. Intact, ventral view. B-C. Macerated, ventral and dorsal views. Scale bars: $0.2 \mathrm{~mm}$.

Genus Zelotes Gistel, 1848

Zelotes hyrcanus sp. nov. urn:1sid:zoobank.org:act:DAE7109D-3408-46FD-98A8-CA3AF3969298

Fig. 27

\section{Diagnosis}

The new species is similar to Z. eugeni Kovblyuk, 2009 and Z. longipes (L. Koch, 1866) by having a similarly shaped atrium and anterior hood. It differs from Z. eugeni by having anterior hoods that are 1.3 times as wide as the atrium (vs almost 2 times). It differs from $Z$. longipes by the longer lateral margins, $2 / 3$ as long as atrium (vs $1 / 2$ ) and the diverging copulatory ducts adjoining to receptacles (vs parallel).

\section{Etymology}

The specific epithet is an adjective and refers to Hyrcanian region, in which the type locality of the new species is located. 


\section{Type material}

\section{Holotype}

IRAN • +; Mazandaran Province, 20 km north of Chalus; May 2015; D. Kasatkin leg.; MHNG.

\section{Description}

\section{Female}

Habitus as in Fig. 27D. Total length 9.33. Carapace 3.01 long, 2.10 wide. Eye sizes and interdistance of PMEs: $\mathrm{AME}=0.08, \mathrm{ALE}=0.10, \mathrm{PME}=0.11, \mathrm{PLE}=0.10, \mathrm{PME}-\mathrm{PME}=0.06$. Carapace, chelicerae, maxillae, labium and sternum black. Chelicerae (Fig. 27E) with 4 pro- and 1 or 2 retromarginal teeth. Legs the same color as carapace and without annulations. Abdomen dark gray, without any patterns. Spinnerets slightly darker than abdomen, uniform in color. Measurements of legs: I: 6.72 (1.98, 1.29, 1.33, 1.14, 0.98), II: 5.85 (1.52, 1.14, 1.13, 1.06, 1.00), III: 5.45 (1.48, 0.80, 0.97, 1.30, 0.90), IV: 8.23 $(1.89,1.33,1.64,2.16,1.21)$.

Epigyne as in Fig. 27A-C. Epigynal plate slightly longer than wide; atrium large, rounded posteriorly and with parallel margins anteriorly; lateral margins $2 / 3$ of atrium's length; anterior part of margins with small hoods, anterior hoods distinct, separated by 0.77 of epigyne length (from posterior margin to anterior hoods); receptacles round, touching each other, diameter almost 4 times smaller than atrium width; copulatory ducts diverging.

\section{Male \\ Unknown.}

\section{Distribution}

Known only from the type locality in Mazandaran Province, northern Iran.
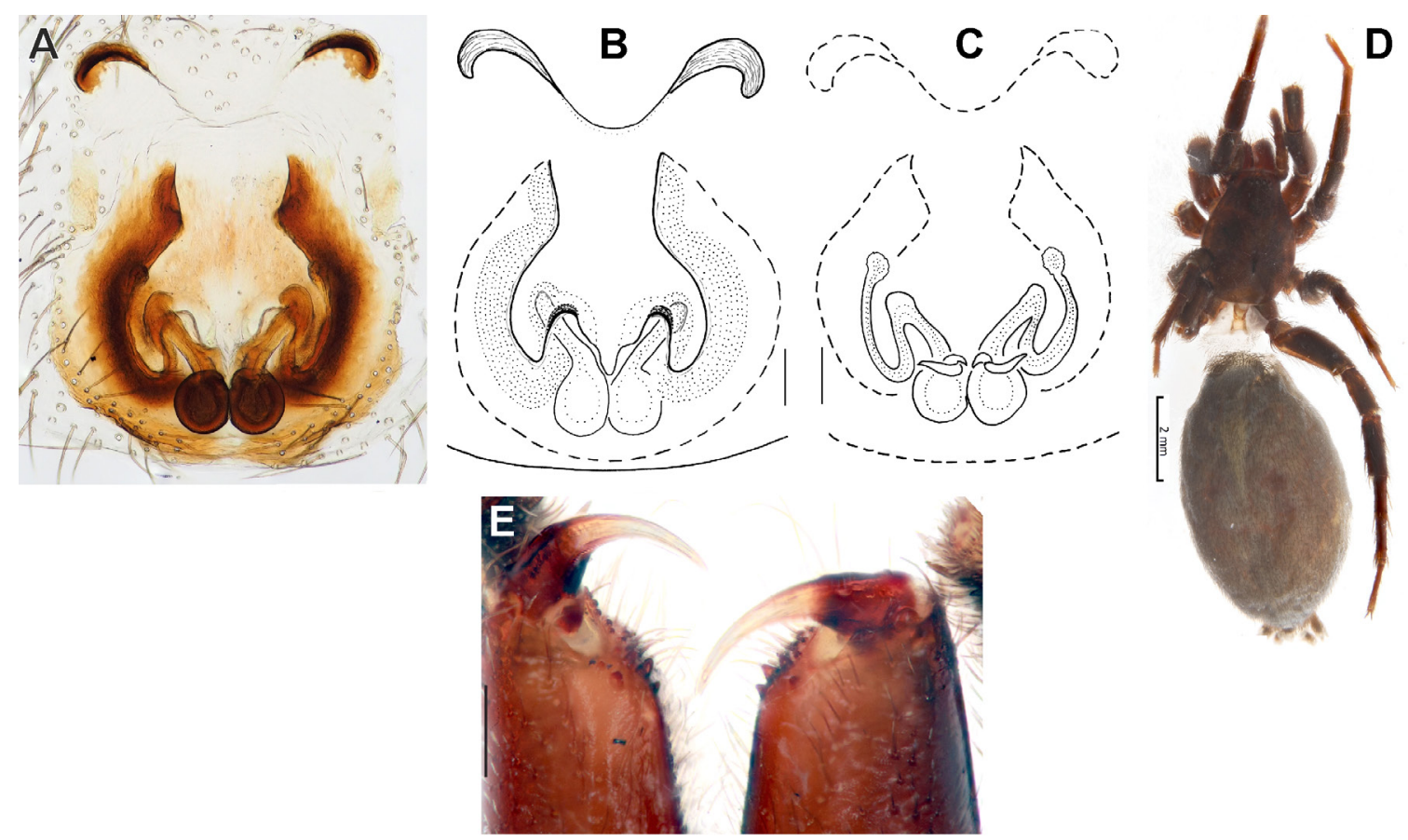

Fig. 27. Zelotes hyrcanus sp. nov., holotype, + (MHNG). A, C. Epigyne, ventral view. B. Epigyne, dorsal view. D. Habitus, dorsal view. E. Chelicerae, posterior view. Scale bars: $B-C=0.1 \mathrm{~mm} ; \mathrm{D}=2 \mathrm{~mm}$; $E=$ $0.2 \mathrm{~mm}$. 


\section{Discussion}

Our results increase the number of ground spiders from Iran to 131 species from 40 genera. Three of these genera (Callipelis, Iranotricha Zamani \& Marusik, 2018 and Zagrotes gen. nov.) are monotypic Iranian endemics. The first two are desert specialists; the surface temperature of the type locality of Iranotricha lutensis Zamani \& Marusik, 2018 (central Lut Desert) has been recorded to be as high as $80.83^{\circ} \mathrm{C}$ (Zamani et al. 2018b; Azarderakhsh et al. 2020), which makes the area the hottest place inhabited by spiders (previously this record was attributed to Death Valley, California, with the highest ground temperature recorded at $56.7^{\circ} \mathrm{C}$; see Mammola et al. 2017).

With 131 species recorded from Iran, Gnaphosidae is currently the most species rich spider family in Iran (Zamani et al. 2021). The number of species recorded from the smaller but better investigated neighboring Turkey is higher (150, see Danışman et al. 2019), and there are about 130 species recorded from the whole Caucasus (Otto 2020). In Europe, 173 gnaphosid species are known from France, and between 150-160 species have been recorded in Spain, Greece and Italy (Nentwig et al. 2021). Considering that the vast majority of Iranian territory remains poorly sampled in regard to spider fauna, and the fact that Gnaphosidae is a spider family consisting of many xerophilous or desert living species, it is reasonable to assume that the true diversity of this family in Iran could be much higher than what is currently known, as random and scattered samplings are still yielding new records or species.

\section{Acknowledgments}

We are grateful to Peter Schwendinger (NHMG), Christoph Hörweg (NHMW), and Peter Jäger and Julia Altman (SMF) for sending us the material deposited in their respective collections, and Alireza Naderi, Parham Beyhaghi, Soheyl Sami, Mojtaba Ezazi, Mehdi Musavi, Mehdi Sheykhi, Mohammad Amiri, Razieh Rafiei-Jahed, Phillippe Ponel, Barbod Safaei-Mahroo, Lida Karami, Amin Hosseinpour and Denis Kasatkin for field assistance and/or providing us with their collected material. Sarah Crews (California Academy of Sciences) kindly checked the English of the final draft.

\section{References}

Al-Khazali A.M. 2020. Berlandina mesopotamica sp. nov. (Araneae: Gnaphosidae): new record of the genus in Iraq. Arachnology 18 (5): 444-446. https://doi.org/10.13156/arac.2020.18.5.444

Al-Khazali A.M. \& Fomichev A.A. 2021. Description of the female of Berlandina mesopotamica (Araneae: Gnaphosidae). Arachnologische Mitteilungen 61: 70-72. https://doi.org/10.30963/aramit6111

Azarderakhsh M., Prakash S., Zhao Y. \& AghaKuchak A. 2020. Satellite-based analysis of extreme land surface temperatures and diurnal variability across the hottest place on Earth. IEEE Geoscience and Remote Sensing Letters 17 (12): 2025-2029. https://doi.org/10.1109/LGRS.2019.2962055

Chatzaki M. 2010. A revision of the genus Nomisia in Greece and neighboring regions with the description of two new species. Zootaxa 2501 (1): 1-22. https://doi.org/10.11646/zootaxa.2501.1.1

Chatzaki M. 2018. On the ground spider genera Marjanus gen. nov., Lasophorus gen. nov. and Turkozelotes Kovblyuk \& Seyyar, 2009 (Araneae: Gnaphosidae) from Greece. Zootaxa 4392 (3): 521-545. https://doi.org/10.11646/zootaxa.4392.3.5

Chatzaki M. \& Van Keer J. 2019. Ground spiders (Araneae: Gnaphosidae, Liocranidae, Prodidomidae) from the Greek islands Rodos, Symi and Karpathos, with the description of new species. Zootaxa 4646 (3): 434-460. https://doi.org/10.11646/zootaxa.4646.3.2

Chatzaki M., Thaler K. \& Mylonas M. 2002. Ground spiders (Gnaphosidae; Araneae) of Crete (Greece). Taxonomy and distribution. I. Revue suisse de Zoologie 109 (3): 559-601.

https://doi.org/10.5962/bhl.part.79611 
Danışman T., Kunt K.B. \& Özkütük R.S. 2019. The Checklist of the Spiders of Turkey. Version 2019. Available from http://www.spidersofturkey.info [accessed 12 Jan. 2021].

Esyunin S.L. \& Zamani A. 2019. Taxonomic remarks on two Drassodes species (Araneae, Gnaphosidae) from Iran. Acta Arachnologica 68 (2): 63-71. https://doi.org/10.2476/asjaa.68.63

Hosseinpour A., Zamani A., Azizi K., Moemenbellah-Fard M.D. \& Soltani A. 2019. Survey of spiders (Arachnida: Araneae) in southwestern Iran, with new records. Ecologica Montenegrina 22: 204-213. https://doi.org/10.37828/em.2019.22.16

Kashefi R., Ghassemzadeh F., Kami H.G. \& Mirshamsi O. 2013. New data on spider fauna from Golestan province, Iran (Arachnida, Araneae). Progress in Biological Sciences 3 (1): 7-22.

Komposch C. 2002. Spinnen, Weberknechte, Skorpione und Walzenspinnen aus dem Iran (Arachnida: Araneae, Opiliones, Scorpiones, Solifugae). In: Gutleb B. \& Wieser C. (eds) Ergebnisse einer zoologischen Exkursion in den Nordiran, 2001: 33-140. Carinthia II 192/112.

Levy G. 1995. Revision of the spider subfamily Gnaphosinae in Israel (Araneae: Gnaphosidae). Journal of Natural History 29 (4): 919-981. https://doi.org/10.1080/00222939500770351

Levy G. 1998. The ground-spider genera Setaphis, Trachyzelotes, Zelotes, and Drassyllus (Araneae: Gnaphosidae) in Israel. Israel Journal of Zoology 44: 93-158.

Levy G. 1999. Spiders of six uncommon drassodine genera (Araneae: Gnaphosidae) from Israel. Israel Journal of Zoology 45: 427-452.

Lissner J. \& Chatzaki M. 2016. A new species of Berinda (Araneae, Gnaphosidae) from the eastern Aegean Islands, Greece. Arachnologische Mitteilungen 51: 9-11. https://doi.org/10.5431/aramit5102

Mammola S., Michalik P., Hebets E.A. \& Isaia M. 2017. Record breaking achievements by spiders and the scientists who study them. PeerJ 5: e3972. https://doi.org/10.7717/peerj.3972

Marusik Y.M., Omelko M.M. \& Koponen S. 2013. Redescription of Pterotricha loeffleri (Roewer, 1955) (Aranei: Gnaphosidae: Gnaphosinae). Arthropoda Selecta 22: 349-352.

https://doi.org/10.15298/arthsel.22.4.05

Marusik Y.M., Fomichev A.A. \& Omelko M.M. 2014. A survey of East Palaearctic Gnaphosidae (Araneae). 1. On the Berlandina Dalmas, 1922 (Gnaphosinae) from Mongolia and adjacent regions. Zootaxa 3827 (2): 187-213. https://doi.org/10.11646/zootaxa.3827.2.4

Mozaffarian F., Tirgari S. \& Bayat-Asadi H. 2000. Investigations on the fauna of spiders in paddy fields of Mazandaran and Gilan provinces. Applied Entomology and Phytopathology 67 (1/2): 51-70. [In Persian.]

Murphy J. 2007. Gnaphosid Genera of the World. British Arachnological Society St Neots, Cambridgeshire.

Namaghi H.S., Safari A., Entezari E. \& Zamani A. 2016. New faunistic records of spiders (Araneae) from northeastern Iran. Zoology and Ecology 26: 18-21. https://doi.org/10.1080/21658005.2015.1104812

Nentwig W., Blick T., Bosmans R., Gloor D., Hänggi A. \& Kropf C. 2021. Spiders of Europe. Version 01.2021. Available from https://www.araneae.nmbe.ch [accessed 11 Jan. 2021]. https://doi.org/10.24436/1

Otto S. 2020. Caucasian Spiders. A faunistic database on the spiders of the Caucasus. Version 10.2020. Available from https://caucasus-spiders.info/ [accessed 13 Jan. 2021].

Panayiotou E., Kaltsas D., Seyyar O. \& Chatzaki M. 2010. Revision of the genus Berinda (Araneae, Gnaphosidae) in the east Mediterranean with the description of two new species. Zootaxa 2362: 44-54. https://doi.org/10.11646/zootaxa.2362.1.2

Roewer C.F. 1928. Araneae. In: Zoologische Streifzüge in Attika, Morea, und besonders auf der Insel Kreta, II. Abhandlungen des Naturwissenschaftlichen Vereins zu Bremen 27: 92-123. 
Roewer C.F. 1955. Die Araneen der Österreichischen Iran-Expedition 1949/50. Sitzungsberichte der Österreichischen Akademie der Wissenschaften (I) 164: 751-782.

Sadeghi H., Ahmadi M., Zamani A. \& Jabaleh I. 2016. A study on the spider fauna of Dargaz and Kalat Counties in Razavi Khorasan Province, Iran (Arachnida: Araneae). Biharean Biologist 10(1): 4-7.

Senglet A. 2012. Civizelotes new genus, and other new or little known Zelotinae (Araneae, Gnaphosidae). Revue suisse de Zoologie 119: 501-528. https://doi.org/10.5962/bhl.part.150203

Seyyar O., Demir H. \& Ok D. 2019. Marjanus Chatzaki, 2018 and Marjanus platnicki (Zhang, Song \& Zhu, 2001) (Araneae: Gnaphosidae) are new records for Turkish spider fauna. Serket 16 (4): 200-202.

WSC. 2021. World Spider Catalog. Version 21.5. Natural History Museum Bern. Available from http://wsc.nmbe.ch [accessed 10 Jan. 2021]. https://doi.org/10.24436/2

Wunderlich J. 1995. Beschreibung einer bisher unbekannten Art der Gattung Scotophaeus Simon aus Österreich (Arachnida: Araneae: Gnaphosidae). Beiträge zur Araneologie 4 (1994): 743-747. [publ. in Dec. 1995]

Zamani A. 2015. The spider collection (Arachnida: Araneae) of the Zoological Museum of the Iranian Research Institute of Plant Protection, with new species records for Iran. Arachnologische Mitteilungen 50: 11-18. https://doi.org/10.5431/aramit5002

Zamani A., Dimitrov D., Weiss I., Alimohammadi S., Rafiei-Jahed R., Esyunin S.L., Moradmand M., Chatzaki M. \& Marusik Y.M. 2020. New data on the spider fauna of Iran (Arachnida: Araneae), part VII. Arachnology 18 (6): 569-591. https://doi.org/10.13156/arac.2020.18.6.569

Zamani A. \& Marusik Y.M. 2017. Six new species of spiders (Arachnida: Araneae) from Iran. Oriental Insects 51 (4): 313-329. https://doi.org/10.1080/00305316.2017.1282386

Zamani A. \& Marusik Y.M. 2018. The first report on the spider fauna (Arachnida: Araneae) of the Lut Desert, Iran. Acta Arachnologica 67 (2): 67-75. https://doi.org/10.2476/asjaa.67.67

Zamani A. \& Mozaffarian F. 2017. Further spider (Arachnida: Araneae) material deposited in the Agricultural Zoology Museum of Iran (AZMI), Iranian Research Institute of Plant Protection. Arachnologische Mitteilungen 54: 8-20. https://doi.org/10.5431/aramit5403

Zamani A., Nikmagham Z., Allahdadi M., Ghassemzadeh F. \& Mirshamsi O. 2014. New data on the spider fauna of Iran (Arachnida: Araneae). Zoology in the Middle East 60 (4): 362-367.

https://doi.org/10.1080/09397140.2014.970383

Zamani A., Mirshamsi O., Jannesar B., Marusik Y.M. \& Esyunin S.L. 2015. New data on the spider fauna of Iran (Arachnida: Araneae), Part II. Zoology and Ecology 25 (4): 339-346.

https://doi.org/10.1080/21658005.2015.1068508

Zamani A., Mirshamsi O., Rashidi P., Marusik Y.M., Moradmand M. \& Bolzern A. 2016. New data on the spider fauna of Iran (Arachnida: Aranei), part III. Arthropoda Selecta 25 (1): 99-114.

https://doi.org/10.15298/arthsel.25.1.10

Zamani A., Mirshamsi O., Dolejš P., Marusik Y.M., Esyunin S.L., Hula V. \& Ponel P. 2017. New data on the spider fauna of Iran (Arachnida: Araneae), Part IV. Acta Arachnologica 66 (2): 55-71.

https://doi.org/10.2476/asjaa.66.55

Zamani A., Mirshamsi O., Kashani G.M. \& Karami L. 2018a. New data on the spider fauna of Iran (Arachnida: Araneae), Part V. Iranian Journal of Animal Biosystematics 13 (2): 183-197. https://doi.org/10.22067/ijab.v13i2.72404

Zamani A., Seiedy M., Saboori A. \& Marusik Y.M. 2018b. The spider genus Pterotricha in Iran, with the description of a new genus (Araneae, Gnaphosidae). ZooKeys 777: 17-41.

https://doi.org/10.3897/zookeys.777.26745 
Zamani A., Tanasevitch A.V., Nadolny A.A., Esyunin S.L. \& Marusik Y.M. 2019. New data on the spider fauna of Iran (Arachnida: Aranei), Part VI. Euroasian Entomological Journal 18 (4): 233-243. https://doi.org/10.15298/euroasentj.18.4.01

Zamani A., Mirshamsi O., Marusik Y.M. \& Moradmand M. 2021. The Checklist of the Spiders of Iran. Version 2021. Available from http://www.spiders.ir [accessed 13 Jan. 2021].

Manuscript received: 21 January 2021

Manuscript accepted: 13 April 2021

Published on: 4 June 2021

Topic editor: Rudy C.A.M. Jocqué

Desk editor: Radka Rosenbaumová

Printed versions of all papers are also deposited in the libraries of the institutes that are members of the EJT consortium: Muséum national d'histoire naturelle, Paris, France; Meise Botanic Garden, Belgium; Royal Museum for Central Africa, Tervuren, Belgium; Royal Belgian Institute of Natural Sciences, Brussels, Belgium; Natural History Museum of Denmark, Copenhagen, Denmark; Naturalis Biodiversity Center, Leiden, the Netherlands; Museo Nacional de Ciencias Naturales-CSIC, Madrid, Spain; Real Jardín Botánico de Madrid CSIC, Spain; Zoological Research Museum Alexander Koenig, Bonn, Germany; National Museum, Prague, Czech Republic. 